\title{
Description and molecular phylogeny of Tethya leysae sp. nov. (Porifera, Demospongiae, Hadromerida) from the Canadian Northeast Pacific with remarks on the use of microtomography in sponge taxonomy
}

\author{
ISABEL HEIM \& MICHAEL NICKEL \\ Institut für Spezielle Zoologie und Evolutionsbiologie mit Phyletischem Museum, Friedrich-Schiller-Universität Jena, Erbertstr. 1, \\ 07743 Jena, Germany.E-mail: isabel.heim@uni-jena.de, m.nickel@uni-jena.de.www.porifera.net
}

\begin{abstract}
The sponge Tethya leysae sp. nov. (Porifera, Demospongiae, Hadromerida, Tethyidae) is a new species from the Canadian Northeast Pacific. Its type locality is the infralittoral around Ohiat Islet, Barkely Sound, Vancouver Island in Canada. Tethya leysae sp. nov. is a medium-sized spherical sponge with a verrucose surface, orange-yellow to light red alive and white with a greyish core in ethanol. The highly variable oxyspherasters $(25-115 \mu \mathrm{m}$ in size, R/C 0.34-0.69) are densely scattered almost throughout the entire cortex. The micrasters comprise acanthoxyspherasters, acanthostrongylasters, acanthotylasters and small oxyspherasters, which are present at low densities throughout the sponge and form a dense layer associated with the exopinacoderm. The megascleres and the auxiliary megascleres comprise oxeas and strongyloxeas. The new species is clearly distinguishable from the closely related T. californiana by the absence of spherules among the micrasters, the lack of an alveolar cortex and the extremely high density of megasters in the cortex. In addition, the $\mathrm{R} / \mathrm{C}$ values of the megasters differ between the two species and the oxyspherasters of $T$. leysae sp. nov. rarely display bent rays. The morphological differences between the species are confirmed by nucleotide and amino acid substitutions within the cytochrome oxidase subunit I (COI) mtDNA gene. Phylogenetic analyses group T. leysae sp. nov. with $T$. californiana, T. actinia and T. minuta, which together form a sister group to a MediterraneanNorth Atlantic species cluster. Morphological analyses of the skeleton included x-ray microtomography $(\mu \mathrm{CT})$ and virtual 3D reconstruction, which was used for the first time in conjunction with the description of a new sponge species. Microtomography permitted the visualization and analysis of spicules within the skeletal context or isolated in silico. The method represents a valuable extension to the sponge taxonomist's toolbox since it allows morphometric measurements in 3D. $\mu \mathrm{CT}$ will thus supplement classical morphological methods such as light and scanning electron microscopy.
\end{abstract}

Key words: Sponges, new species, synchrotron radiation based x-ray micro computed tomography, in silico morphometry, COI, maximum likelihood, Bayesian analysis

\section{Introduction}

The invention of the microscope in the $17^{\text {th }}$ century made it possible to study internal skeletal structures in sponges. Ever since, microscopic mineral spicules and the architecture of the skeleton have been as useful as macroscopic morphological characters such as colour and shape, texture and the like in the determination of sponges. In the $19^{\text {th }}$ century many sponge species, e.g. Chondrosia reniformis Nardo, 1847, Clathrina clathrus (Schmidt, 1864), Dysidea fragilis (Montagu, 1818) and, Guitarra fimbriata, Carter, 1874 were described, and often regarded as cosmopolitan due to their wide geographical range (Boury-Esnault et al. 1993). However, in recent years many cosmopolitan species have turned out to be 'sponge taxonomist traps', in fact representing complexes of cryptic species that are genetically distinct but which display low variability in most of their morphological characters. In the 1980s molecular techniques were used for the first time to sort among morphotypes thought to pertain to a single species (Solé-Cava \& Thorpe 1986). Allozyme electrophoresis which defines products of individual gene loci was used to calculate gene frequencies and estimate exchange 
rates between morphotypes (Solé-Cava \& Thorpe 1986, 1987). Between 1986 and 2001, around 15 papers were published using allozyme electrophoresis (Xavier et al. 2009), revealing over 10 new species previously unknown to science (Solé-Cava \& Thorpe 1986; Solé-Cava et al. 1991; Klautau et al. 1994; Boury-Esnault et al. 1999). Molecular biology techniques played a decisive role in the discovery of these cryptic or sibling species because they are difficult to identify on the basis of phenotypic characters alone (Blanquer \& Uriz 2008). In recent years, the use of DNA markers such as 28S, 18S, ITS and COI in sponge research has increased gradually but notably, and many more cryptic species have been revealed (Wörheide et al. 2000; Miller et al. 2001; Nichols \& Barnes 2005; Duran \& Rützler 2006; Wulff 2006; Blanquer \& Uriz 2007, 2008; Blanquer et al. 2008).

At present, Tethya Lamarck, 1815 (Tethyidae: Hadromerida: Demospongiae) still contains a number of species such as T. aurantium (Pallas, 1766) or T. seychellensis (Wright, 1881) which are generally regarded as (almost) cosmopolitan. Tethya aurantium in particular was originally thought to be extremely widespread, but it seems to be more appropriate to regard it as a species complex of still unknown composition. The species was/is reported from the entire Mediterranean and Caribbean seas, from Ireland, Great Britain, California, Korea, New Zealand and other places (de Laubenfels 1932; Forster 1958; Bergquist et al. 1970; Bergquist \& Bedford 1978; Sim 1981; Costeloe et al. 1986; Sarà 1998; Bell \& Barnes 2001; Heim et al. 2007b; Van Soest et al. 2009). Some present taxonomic incongruences within Tethya trace back to debates on the status of several species in the early $20^{\text {th }}$ century. Additionally, the 'lumping' taxonomic decisions of Topsent (1918) and Burton (1924) increased these incongruences. Both factors hindered work to separate "cosmopolitan" species. Tethya aurantium, for instance, was the only Tethya species recognized to inhabit European waters for around 200 years.

However, a closer examination of the relevant morphological characters and, in recent years, the use of molecular techniques has allowed scientists to distinguish four Tethya species in Europe. In 1965, T. citrina Sarà \& Melone, 1965 was described for the Mediterranean Sea. It was formerly regarded as a colour variant of T. aurantium. A third European Tethya, T. norvegica Bowerbank, 1872, was confirmed in 1992. Initially described by Bowerbank, it was subsequently not accepted as a valid species but believed to be another variant of T. aurantium, until a thorough re-examination of the species re-established its status as a valid species (Sarà et al. 1992). The fourth and most recent European species in the T. aurantium complex is a clear case of a cryptic species first assigned to T. norvegica, but recently described as T. hibernica Heim, Nickel, Picton \& Brümmer, 2007 on the basis of molecular markers (Heim et al. 2007b). The European T. aurantium is distributed across the Mediterranean Sea and the East Atlantic and partly shares its geographic range with $T$. citrina (Sarà et al. 1989; Heim et al. 2007b). The sympatric occurrence of some European species of Tethya complicates the identification of sponges in the field and comprises the following sympatric combinations: $T$. aurantium / T. citrina in the Mediterranean (Sara \& Gaino 1987), and T. citrina / T. norvegica / T. hibernica in Northeast Atlantic areas (Heim et al. 2007b).

For the temperate waters of the Pacific coast of North America one species belonging to the T. aurantium complex is described: T. californiana de Laubenfels, 1932 (Sarà \& Corriero 1993). T. californiana was originally described from Southern California as T. aurantia var. californiana (de Laubenfels 1932). De Laubenfels regarded it to be a variant or subspecies due to its greater average spicule size and the preponderance of strongyles rather than styles among the megascleres. Sarà \& Corriero (1993) proposed $T$. californiana as a valid species on the basis of differences in cortical and spicular characters in comparison to T. aurantium, i.e. in T. californiana the aquiferous system and the related megaster skeleton are specialized in an uncommon way, displaying an alveolated exocortex surrounding a lacunar endocortex. A number of scientific and non-scientific reports of T. californiana (or its unaccepted synonym T. aurantia) off the north east Pacific coast of North America can be found in biodiversity databases (GBIF 2009), publications (Austin et al. 1999-2007) and on websites related to SCUBA diving (e.g. Murch 2009). Records were found for British Columbia (e.g. Barkeley Sound and Hornby Island) and California (e.g. Carmel Bay, San Miguel Island, Tanner Bank and the Gulf of California).

The total number of Eastern Pacific Tethya species to be found along the Pan-American coast currently stands at ten. Along the shores of Mexico (including the Gulf of California), seven species occur: T. ensis 
Sarà, Gómez \& Sarà, 2001, T. mexicana Sarà, Gómez \& Sarà, 2001, T. ovum Sarà, Gómez \& Sarà, 2001, T. paroxeata Sarà, Gómez \& Sarà, 2001, T. socius Sarà, Gómez \& Sarà, 2001, T. californiana and T. taboga De Laubenfels, 1936. The latter is also common along the coasts of Panama. Two additional Tethya species are reported for the Galapagos Islands, namely T. sarai Desqueyroux-Faúndez \& van Soest, 1997 and $T$. strongylata Sarà, Bavestrello \& Calcinai, 2000, and T. papillosa (Thiele, 1905) has been found in Calbuco in Chile (Sarà et al. 2001).

Here we describe Tethya leysae sp. nov., which occurs in the same biogeographic region as and was formerly believed to belong to the species T. californiana, as a cryptic new species for the Pacific coast of British Columbia, Canada. We provide the results of our morphological analysis, in the course of which we used synchrotron radiation-based microtomography for the first time to investigate skeletal characters (Nickel et al. 2006a; Nickel et al. 2006b), and also discuss the molecular relationship between Tethya leysae sp. nov. and the most closely related species T. californiana on the basis of cytochrome oxidase subunit I (COI). We address the problem of the geographical distribution of Tethya species and discuss morphological characters which distinguish the two species.

\section{Material and methods}

Sponge material. Single specimens of Tethya leysae sp. nov., were sampled by Prof. Dr. Sally P. Leys (University of Alberta, Canada) on rocky hard bottom substrate in the shallow Infralittoral near Ohiat Islet, Northeast Pacific, Barkley Sound, Bamfield, Vancouver Island, British Columbia, Canada by SCUBA diving. The collection of the present sponge material aimed specifically at sampling Tethya sp. from the Bamfield area for a comparative functional study of one of us $(\mathrm{MN})$ in another context. The samples are deposited in the sponge collections of the British Museum of Natural History London, United Kingdom (holotype NHM 2009.5.1.1) and the Phyletisches Museum of Friedrich-Schiller-Universität Jena, Germany (paratype, PMJ Porif 287). The COI sequence of the holotype and the species description were submitted to the Sponge Barcoding Database (www.spongebarcoding.org; record number 222). For comparison we morphologically examined one of the two syntypes of T. californiana described by De Laubenfels: BMNH 29.8.22.15.

DNA extraction and PCR amplification. In preparation for the DNA isolation of the two type specimens we dehydrated the samples stored in $70 \%$ ethanol by immersing them in a graded ethanol series from $80 \%$ to $100 \%$. The samples were then frozen in liquid nitrogen. For DNA extraction the DNeasy Tissue Kit (Qiagen, Hilden, Germany) was used according to the manufacturer's instructions. We amplified a part of the mitochondrial cytochrome oxidase subunit I using the universal primer from Folmer et al. (1994) in $50 \mu 1$ total reaction volume, with $1 \mu \mathrm{l}$ of each primer $(10 \mu \mathrm{M}), 4 \mu \mathrm{l}$ dNTPs $(2.5 \mathrm{mM}), 5 \mu \mathrm{l} 10 \times$ buffer containing 15 $\mathrm{mM} \mathrm{MgCl} 2,1.25 \mathrm{U}$ Taq polymerase (TaKaRa BIO INC., Shiga, Japan) and $4 \mu 1$ template DNA. An initial denaturation at $94^{\circ} \mathrm{C}$ for 2 min was followed by 35 cycles $\left(94^{\circ} \mathrm{C}\right.$ for $50 \mathrm{~s}, 40^{\circ} \mathrm{C}$ for $55 \mathrm{~s}$ and $72^{\circ} \mathrm{C}$ for $\left.1 \mathrm{~min}\right)$, and a final extension at $72^{\circ} \mathrm{C}$ for $7 \mathrm{~min}$. All PCR reactions were conducted on a Mastercycler Personal (Eppendorf). The PCR products were cleaned with the NucleoSpin Extract Kit (Machery-Nagel), ligated into pCR ${ }^{\circledR} 4-T O P O \circledR$ vector (Invitrogen) and transformed via heat shock into competent Escherichia coli One Shot ${ }^{\circledR}$ TOP10 cells (Invitrogen). Plasmid DNA was isolated using NucleoSpin Plasmid Quick Pure Kit (Machery-Nagel). Sequencing was performed by AGOWA GmbH (Berlin, Germany). The nucleotide sequence data have been deposited in the GenBank nucleotide sequence database under the accession numbers GQ292532 (holotype) and GQ292533 (paratype).

Molecular data analysis and phylogenetic calculations. All sequences were checked via BLAST searches in GenBank for possible contaminations (http://www.ncbi.nlm.nih.gov/BLAST/). Nucleotide sequences were edited using Geneious 4.5.3 (Drummond et al. 2009) and translated into amino acid sequences using NCBI ORF Finder, making use of the mould, protozoan and coelenterate mitochondrial genetic code table (Tatusov \& Tatusov 1988-2009). Alignments of the DNA sequences and the amino acid sequences were performed using the MUSCLE alignment algorithm (Edgar 2004) implemented in Geneious 4.5.3. A phylogenetic tree was calculated using MrBayes 3.1.2 (Ronquist \& Huelsenbeck 2003). For sequence 
data we used the GTR $+\mathrm{G}$ model, calculated using MrModeltest 2.2 (Nylander et al. 2004). We ran four Markov chains for one million generations and sampled every 100 generations to calculate a posterior probability distribution of 10.001 trees. Posterior probabilities were computed by constructing a 50\% majority rule consensus tree out of the stationary trees (i.e. the trees saved after 'burn-in' trees are excluded). In addition to the Bayesian approach we calculated a maximum likelihood (ML) tree using RAxML 7.0.4 (Stamatakis et al. 2008) via RAxML Blackbox server with GTR as the best-fit model of DNA substitution, followed by a bootstrap search with 100 replicates. We included all available COI sequences from members of Tethya. The majority of them were sequenced by us in the context of previous research projects (Heim et al. 2007a; Heim et al. 2007b). We defined Placospongia sp. (AY094604) as outgroup, for the following reasons: 1. Placospongiidae and Tethyidae are both included in the order Hadromerida (Hooper \& Van Soest 2002b); 2. Among the available sequences of Hadromerida (which are determined at least to the genus level) Placospongia sp. (AY094604) seems to represent the sister group of the members of Tethyidae (see RAxML COI "Folmer" nucleotide tree V 090612 at Sponge Genetree Server; Erpenbeck et al. 2008); 3. We presently lack alternative samples of Tethyidae or other Hadromerida which are suitable for COI sequencing. All trees were rooted with the outgroup and presented graphically using TreeView 1.6.6 (Page 1996).

Spicule preparation, imaging and morphometrics. Spicule slides from both holotype and paratype were obtained by dissolving sponge fragments in boiling nitric acid (Kelly-Borges \& Pomponi 1992). After mounting the cleaned spicules on microscopic slides, we imaged them using an Olympus BH-2 light microscope (LM, brightfield) (Olympus, Hamburg, Germany) and a Coolpix 990 digital camera attached to the microscope. For SEM analysis, cleaned spicules were spread onto glass cover slides mounted on SEM aluminum sample stubs and subsequently sputtered with gold using an EMITECH K500 sputter coater (Ashford, GB). Digital scanning electron micrographs were taken using a digital Philips XL-30 ESEM (Philips, Germany) scanning electron microscope at $10 \mathrm{kV}$. On the basis of the digital LM and SEM images, spicules were measured using ImageJ (Rasband 1997-2009). For megasters, we calculated the ratio between the length of the ray and the radius of the centre of the spheraster $(\mathrm{R} / \mathrm{C})$ using Microsoft Excel. Statistical analyses (descriptive statistics; Kolmogorov-Smirnov test on normal distribution; independent t-tests) were performed using WinSTAT for Excel.

Skeleton and tissue preparation and imaging. In preparation for our study of skeletal architecture and spiculation, we embedded slices of sponge tissue from both holotype and paratype in SPURR (Plano, Wetzlar, Germany; see Boury-Esnault et al. 2002). After sanding the resin slices down to around $1-2 \mathrm{~mm}$ thickness, the general structure of the sponge was imaged using the Olympus BH-2/Coolpix set-up.

For synchrotron radiation-based x-ray microtomography (Nickel et al. 2006a; Nickel et al. 2006b), some of the SPURR embedded sponge tissue of both type specimens was cut into slender cylinders of $2.5 \times 30 \mathrm{~mm}$ (diameter $\mathrm{x}$ length) to make them compatible with microtomography scanning conditions. Sample cylinders were glued to a microtomography sample holder and SR- $\mu \mathrm{CT}$ was performed at HASYLAB (Hamburger Synchrotronstrahlungslabor) beamline BW2 at the Deutsches Elektronen-Synchrotron DESY (Beckmann et al. 2004) using monochromatic X-rays at a photon energy of $16.5 \mathrm{keV}$. Radiograms $(\mathrm{n}=720)$ were taken at equal intervals between 0 and $\pi$ (average exposure time of $9.5 \mathrm{~s}$ ). Stacks of $\geq 1,024$ images were calculated from each set of radiograms using the tomographic reconstruction algorithm 'back projection of filtered projections' (Huesman et al. 1977). We obtained 3D voxel data with a measured voxel size of $(2.69 \mu \mathrm{m})^{3}$.

Original SR- $\mu \mathrm{CT}$ raw image data were converted to uncompressed 8-bit Bitmap stacks by segmenting grey value information from the most informative 32-bit floating point raw data using ImageJ. Skeletons were 3D-rendered from reconstructed image stacks using VGStudioMax 2.0 (64-bit version, Volume Graphics) and the volume rendering algorithm "Scatter HQ".

\section{Results}

\section{Systematics}

Order Hadromerida Topsent, 1900 
Family Tethyidae Gray, 1867

Genus Tethya Lamarck, 1814

Type species: Tethya aurantium Pallas, 1766

\section{Tethya leysae sp. nov.}

Holotype: NHM 2009.5.1.1, Leg. Sally P. Leys, 25.06.2003.

Paratype: PMJ Porif 287, Leg. Sally P. Leys, 27.09.2006

Type locality: Rocky hard bottom substrate in the shallow Infralittoral (10 - $25 \mathrm{~m}$ depth) near Ohiat Islet, Northeast Pacific, Barkley Sound, Bamfield, Vancouver Island, British Columbia, Canada (Fig. 1), coordinates 4851'3.00" N, 51'3" 125'11'60.00" W.

Diagnosis. Tethya leysae sp. nov. is the only Tethya species in the NE Pacifc possessing a massive uniform cortex with few lacunae and densely packed megasters (oxyspherasters 41-115 $\mu \mathrm{m}$; R/C 0.41), which are larger and display shorter rays compared to T. californiana. It also lacks the alveolar exocortex and the bilayered megastrer distribution typical for T. californiana; Two categories of oxeas/strongyloxeas, both slightly larger/thicker than in T. californiana: main (1580-2540 $\mu \mathrm{m} \times 18-53 \mu \mathrm{m})$ and auxiliary (490-1490 $\mu \mathrm{m} \times 7-30)$, lacking tylostrongyles.

Etymology. We have chosen the name in honor of Prof. Dr. Sally P. Leys, Edmonton, BC, Canada, who collected and kindly provided the type specimens and is an inspiring colleague and friend.

Description. General body morphology. The body is spherical, with a diameter of $5 \mathrm{x} 4 \mathrm{~cm}$ (holotype; Fig 2A). Sections show an unambiguous division into a cortex region and a choanosomal core (Fig. 3A). The colour in life is orange-yellow to light red (Fig. 2C). The colour in alcohol is white, with a greyish core (Fig. 2A). In living specimens, the body is slightly contractile. However, the overal body consistency is incompressible. The verrucose surface is frequently loaded lightly with sediment. The surface lacks tubercles, filaments and stalked buds (at least they have not been found in the examined material). The cortex is dense and compact, with 3-6 mm in thickness. It lacks lacunae, but is packed with megasters (Figs. 3 and 4).

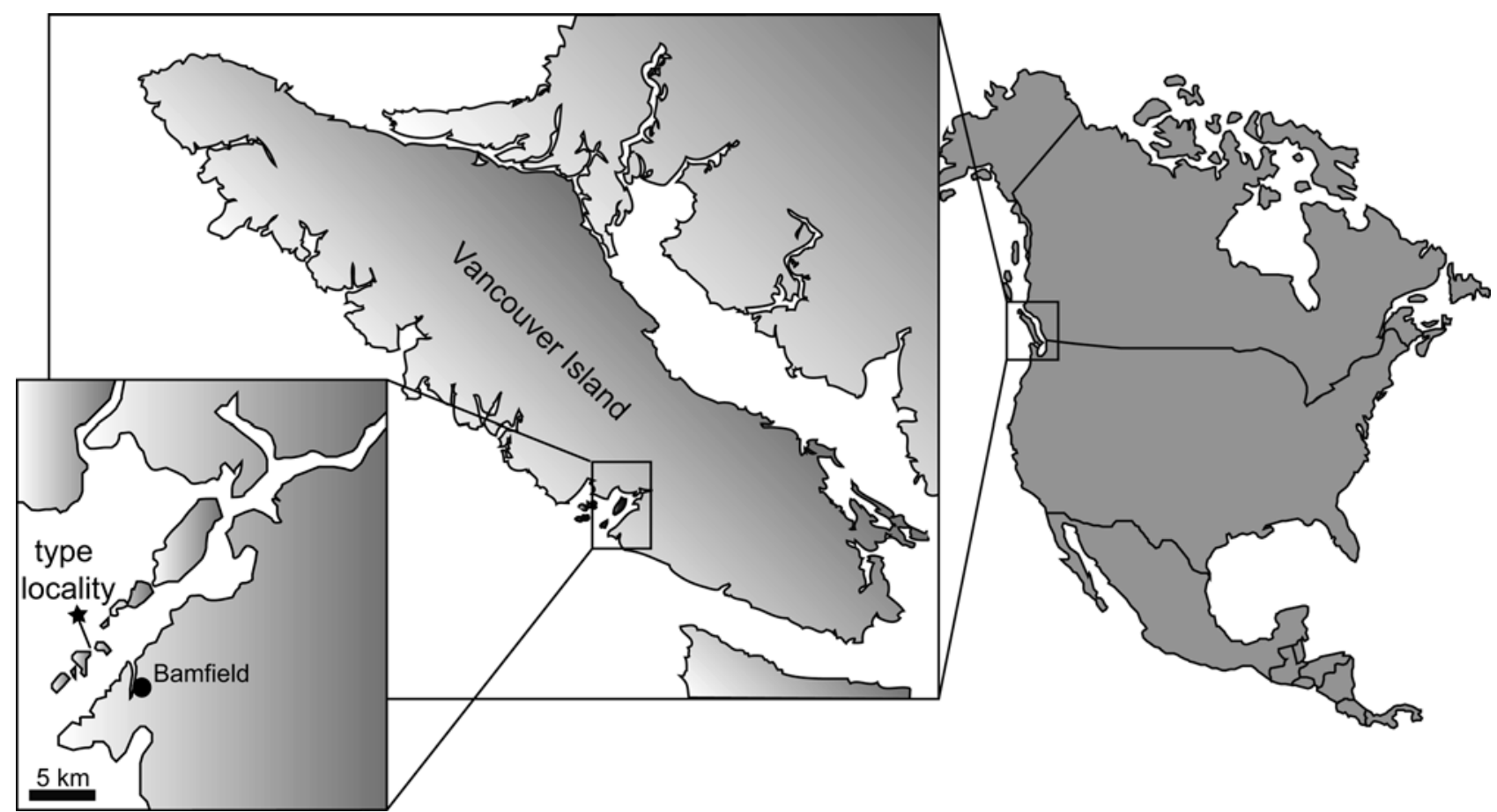

FIGURE 1. Type locality of T. leysae sp. nov. in the Northeast Pacific, around Ohiat Islet, Barkley Sound, near Bamfield, Vancouver Island, British Columbia, Canada, North America. 

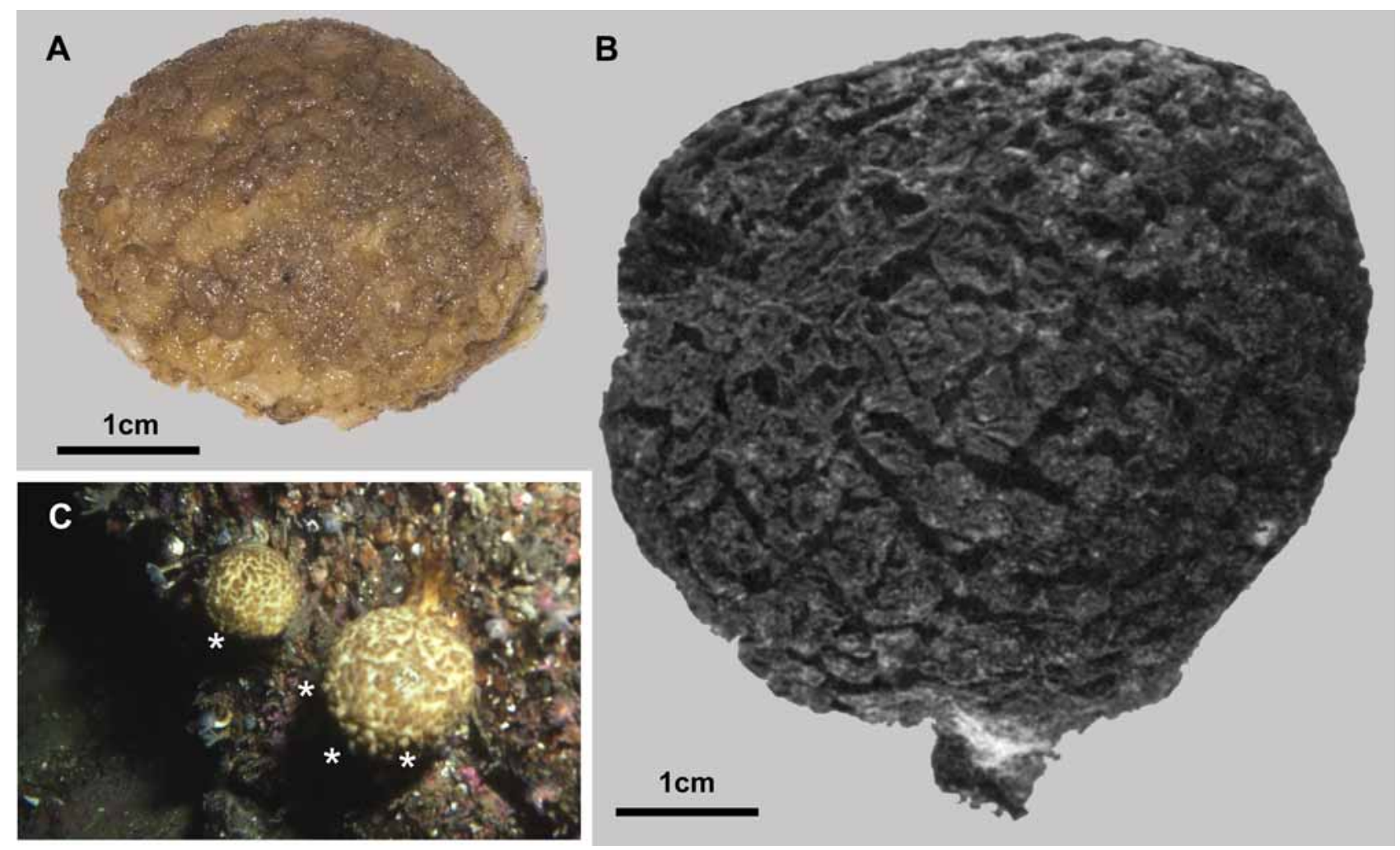

FIGURE 2. A- B. True to scale comparison between the habitus of T. leysae sp. nov. (A, paratype) and T. californiana (B; figure modified from Sarà \& Corriero, 1993). C. Tethya leysae sp. nov in situ in Barkley Sound. Asterisks indicate stalkless buds. The image is a scan of a diapositive; neither the used film material nor the scanner was color-calibrated; therefore, the colors might deviate from natural colors (image courtesy of S. Leys, Edmonton).

Skeletal morphology. The dense radiate bundles of main megascleres (oxeas and strongyloxeas) display diameters between 400-600 $\mu \mathrm{m}$ (see sections, Fig. 3C, F; and microtomographic reconstructions, Fig. 4A, B). The bundles terminate in compact cortical fans which are formed by the main and auxiliary megascleres and make up broad cortical tubercles (Figs. 3B) which contribute to the external verrucose appearance. Groups of auxiliary megascleres are also present interstitially in the choanosome between the main bundles (Fig. 3C). The megasters (spherasters/oxyspherasters) are evenly and densely scattered throughout the whole cortex (Figs. 3B, 3F, 4), but almost lacking in the peripheral 200-500 $\mu \mathrm{m}$ of the cortex (Fig. 3D) and in some basal parts of the cortex near the cortical-choanosomal boundary (Fig. 3E). Micrasters form a discrete layer allocated in the exopinacoderm surface (Fig. 3D) and are most dense in the peripheral cortex. In addition, micrasters are evenly but sparsely distributed throughout the cortex and the choanosome.

Spicules. The main megascleres are constituted by oxeas, anisostrongyles and strongyloxeas (Fig. 5), $1580-2540 \mu \mathrm{m}(2049 \pm 259 \mu \mathrm{m} ; \mathrm{n}=40)$ in length, $18-53 \mu \mathrm{m}(34 \pm 7 \mu \mathrm{m} ; \mathrm{n}=40)$ in diameter. Auxiliary megascleres are constituted by oxeas, anisostrongyles and strongyloxeas, 490-1490 $\mu \mathrm{m}(1055 \pm 215 \mu \mathrm{m}$; $\mathrm{n}=128)$ in length, $7-30 \mu \mathrm{m}(19 \pm 5 \mu \mathrm{m} ; \mathrm{n}=128)$ in diameter. Main and auxiliary megascleres form two significantly different length categories (independent t-test, $p<0.001$; Fig. $6 \mathrm{~B}$ ), both of normal distribution (Kolmogorov-Smirnov test).

The megasters are represented by spherasters to oxyspherasters of varying size and morphology, as evidenced by SEM and microtomography reconstructions (Figs. 5B, C, 6A and 7C, Tab. 1). Cortical megasters (Fig. 5B) display 8-20 rays and are 41-115 $\mu \mathrm{m}(84 \pm 12 \mu \mathrm{m} ; \mathrm{n}=40)$ in diameter with R/Cs of 0.34$0.69(0.46 \pm 0.07 ; \mathrm{n}=227)$. Choanosomal megasters (Fig. $5 \mathrm{C}$ ) display $12-18$ rays and are $24-81 \mu \mathrm{m}$ in diameter, with $\mathrm{R} / \mathrm{Cs}$ of $0.25-0.81(0.41 \pm 0.1 ; \mathrm{n}=85)$. The form of the rays varies in both regions from slender to stout (Fig. 5B, C). A Kolmogorov-Smirnov test (independent t-test, $\mathrm{p}<0.001$ ) suggests that choanosomal oxyspherasters size is significantly smaller than in cortical megasters. 

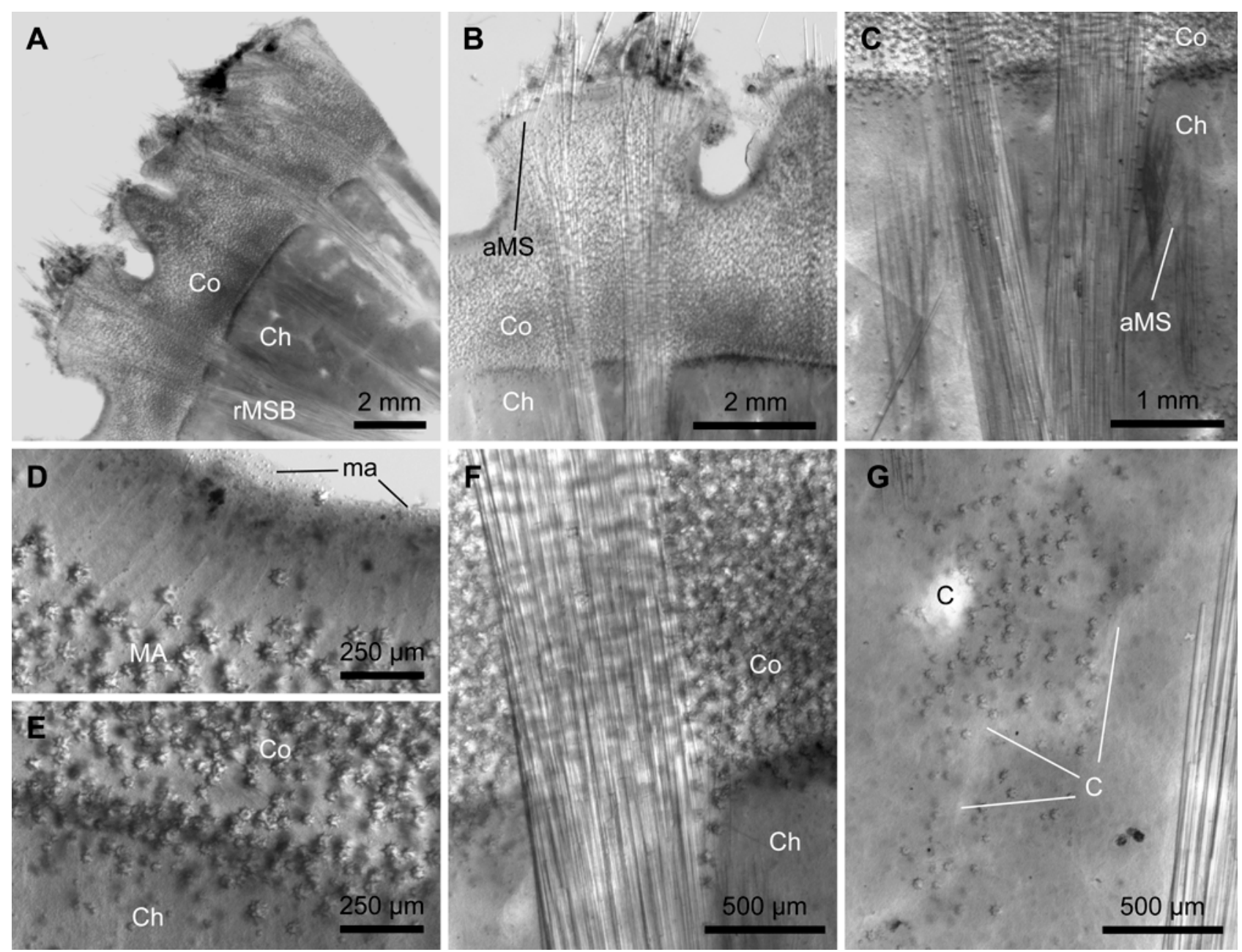

FIGURE 3. Skeletal and overall anatomy of T. leysae sp. nov. (resin slice preparation of the holotype). A. Cross section through cortex $(\mathrm{Co})$ and choanosome $(\mathrm{Ch})$; radial megasclere bundles (rMSB) fan out slightly in the peripheral cortex region. B. - C. Details of the cortex (B) and choanosome (C). The cortex appears solid with almost no subdermal lacunae; it is densely filled with megasters, in contrast to the very low megaster density of the choanosome. Auxiliary megascleres (aMS) are present in the cortical megasclere bundle fans and separately or grouped in the choanosome. D. G. Asters in the cortex and the choanoderm; peripheral micrasters (ma) are associated with the exopinacoderm (D); megasters (MA) dominate the cortex; the average distance between megasters is lower than one megaster diameter (D \& E, see Fig. 4); A peripheral cortical layer $200-400 \mu \mathrm{m}$ thick is almost completely free of megasters (D), subcortical lacunae are present near the inner cortical boundary, thus appearing partly free of megascleres (E); the choanoderm is largely free of megasters $(\mathrm{E}-\mathrm{F})$ or they show up in clouds $(\mathrm{G})$, with a much lower density compared to the cortex.

Micrasters (Fig. 5D) fall into four categories: acanthoxyspherasters (Fig 5D, top left), 10-19 $\mu \mathrm{m}$ in diameter with 10-12 rays (the main category); acanthostrongylasters (Fig. 5D, top middle) $8-18 \mu \mathrm{m}$ in diameter, with 8-12 rays; a few acanthotylasters with only slight terminal knobs (Fig. 5D, top right), 6-8 $\mu \mathrm{m}$ in diameter, with 10-14 slightly spinulated rays; and small oxyspherasters (Fig. 5D, bottom), 4-10 $\mu \mathrm{m}$ in diameter, with $10-15$ slender rays.

Molecular characters. The nucleotide sequences of the cytochrome oxidase subunit I (Folmer fragment) are accessible in Genbank (holotype: GQ292532; paratype: GQ292533) and at www.spongebarcoding.org (record no. 222).

The base pair exchanges in the COI fragment and the deduced amino acid sequences (Tab. 2) clearly distinguish T. leysae sp. nov. from T. californiana (4 nt/2 aa), T. minuta Sarà, Sarà, Nickel \& Brümmer, 2001 (22 nt/3 aa) and T. actinia (18 nt/3 aa). 

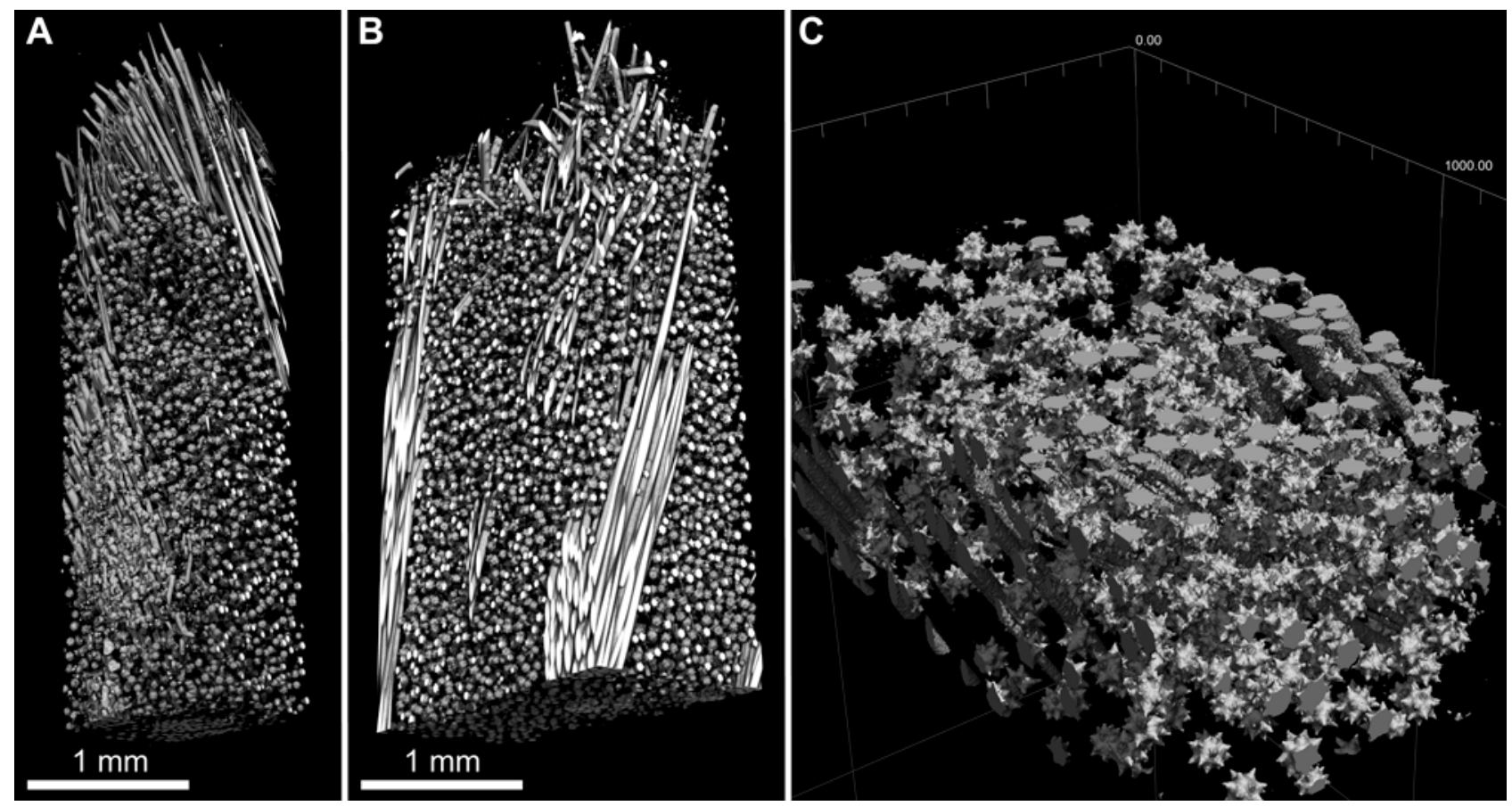

FIGURE 4. Virtual 3D reconstructions of the cortical skeleton of T. leysae sp. nov. (holotype) imaged using synchrotron radiation-based x-ray micro computer tomography (SR $\mu \mathrm{CT}$ ). The massive megasclere bundles reach diameters of up to $500 \mu \mathrm{m}$; there is no free space between asters and megasclere bundles as sometimes seen in other Tethya species; patchy aster-free regions are occupied by canals (tissue not visible in spicule-optimized SR $\mu$ CT, see Nickel et al. $2006 a$, b). A. - B. Block diagrams of cortex preparations from the holotype (A) and the paratype (B). C. Detail cropped from the paratype (coordinate system in $\mathrm{mm}$ ). Additional 3D-renderings of the holotype as well as the paratype are available upon request.
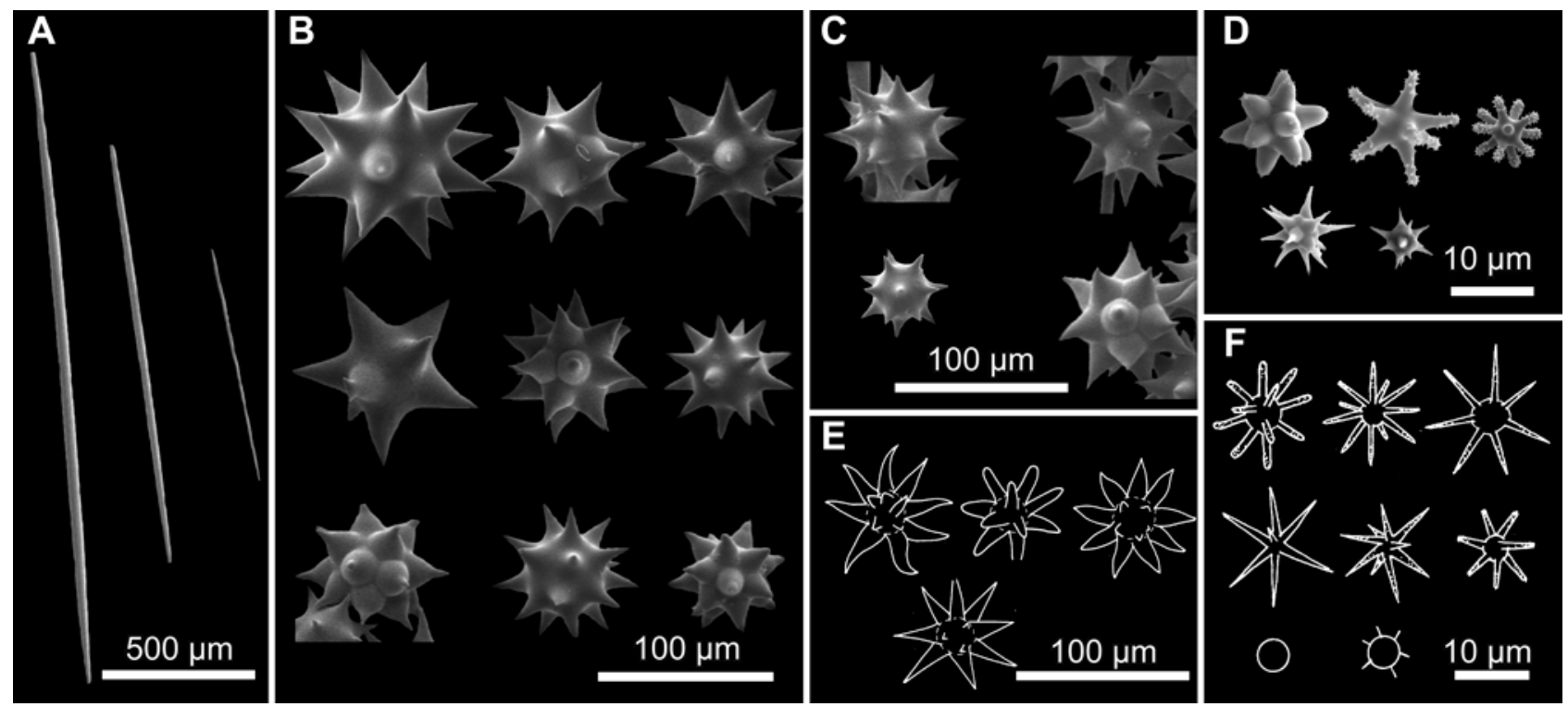

FIGURE 5. Spicule types of T. leysae sp. nov. (A-D; SEM micrographs) in comparison to T. californiana (E-F; drawings modified from Sarà \& Corriero 1993, re-evaluated by own light microscopy of spicule preparations from the specimen BMNH 29.8.22.15.). A. Main and auxiliary megascleres. B. The highly variable cortical megasters. C. Choanodermal megasters. D. Micrasters. E. Megasters. F. Micrasters. 
Reproduction. Asexual reproduction by bud formation near the sponge surface is indicated (Fig. 2C; asterisks). No data exist to date on the sexual reproduction of T. leysae sp. nov.

Ecology. The type habitat at Barkley Sound is infralittoral hard bottom influenced by strong tidal changes such as regular periods of strong currents. Usually, T. leysae is found in aggregates of several specimens (presumably due to asexual reproduction by budding). Larger specimens of up to $8 \mathrm{~cm}$ diameter sometimes cluster in sheltered small canyons of wave exposed areas. Tethya leysae sp. nov. is most abundant in depths between 15-20 m with moderate water flow but no direct wave exposure or current. It usually lives in lighted conditions and on shaded rocks, but avoids dark habitats.

Specimens of T. leysae sp. nov. are frequently found to be covered by debris which might be particulate organic matter, but also algae and other small epibionts like foraminifers.

In some areas of Barkley Sound, it is the most obvious subtidal sponge. Other common sponges are Neopetrosia vanilla (de Laubenfels ,1930) and Cliona sp. (for a species list compare Austin et al. 1999-2007).

Distribution. At present, T. leysae sp. nov. has only been reported for its type locality Barkley Sound, near Bamfield, British Columbia, Canada. It is likely to occur more widely along the North American Pacific coast but its biogeographical limits are presently not known.

Related species. Comparative morphology (general anatomy, skeleton structure, megasclere and microsclere sizes, forms and distribution) suggests that $T$. leysae sp. nov. might be closely related to $T$. aurantium, T. robusta (Bowerbank, 1873) and T. californiana.

At present, T. californiana seems to be the only species which eventually occurs sympatrically. However, T. leysae sp. nov. can be clearly distinguished from T. californiana by the lack of an alveolar cortex and the extremely high density of megasters in the cortex. Another striking difference is the megaster morphology. Their R/C values differ significantly between T. californiana and T. leysae sp. nov. (Tab. 1) and the oxyspherasters of the latter rarely display bent rays. In addition, spherules have not been found among the micrasters of T. leysae sp. nov. However, this character can only be accessed by extensive and very careful study of spicule preparations. In addition to the morphological differences between $T$. californiana and $T$. leysae sp. nov., extensive nucleotide (4 nt) and amino acid ( 2 aa) exchanges are present within the molecular marker COI (Tab. 2).

Tethya leysae sp. nov. also differs from T. aurantium in respect to cortex architecture, which is more massive and much more densely packed with megasters in the new species. In comparison to T. aurantium, the variance in relative ray length of the megasters is higher: while T. aurantium displays spherasters, $T$. leysae sp. nov. displays a range from spherasters to oxysherasters (compare data in Sarà \& Melone 1965; Sarà et al. 1992). In addition to the morphological differences between T. aurantium and T. leysae sp. nov., extensive nucleotide (52 nt) and amino acid (4 aa) exchanges are present within the molecular marker COI (Tab. 2).

Tethya robusta seems to be the species with the most similar cortical architecture (Bowerbank 1873; Sarà \& Sarà 2004), since in both species, megasters are so closely packed "that the rays of each pass between those of the adjoining ones, and the whole become, as it were, cemented into a solid mass" (Bowerbank 1873). However, the megasters in T. robusta display a much higher number of rays (24-32) than those of T. leysae sp. nov. Both species also differ in micraster types: T. leysae sp. nov. lacks the fine rayed oxyasters of T. robusta which in turn lacks the stout acanthoxyspherasters of T. leysae sp. nov. 

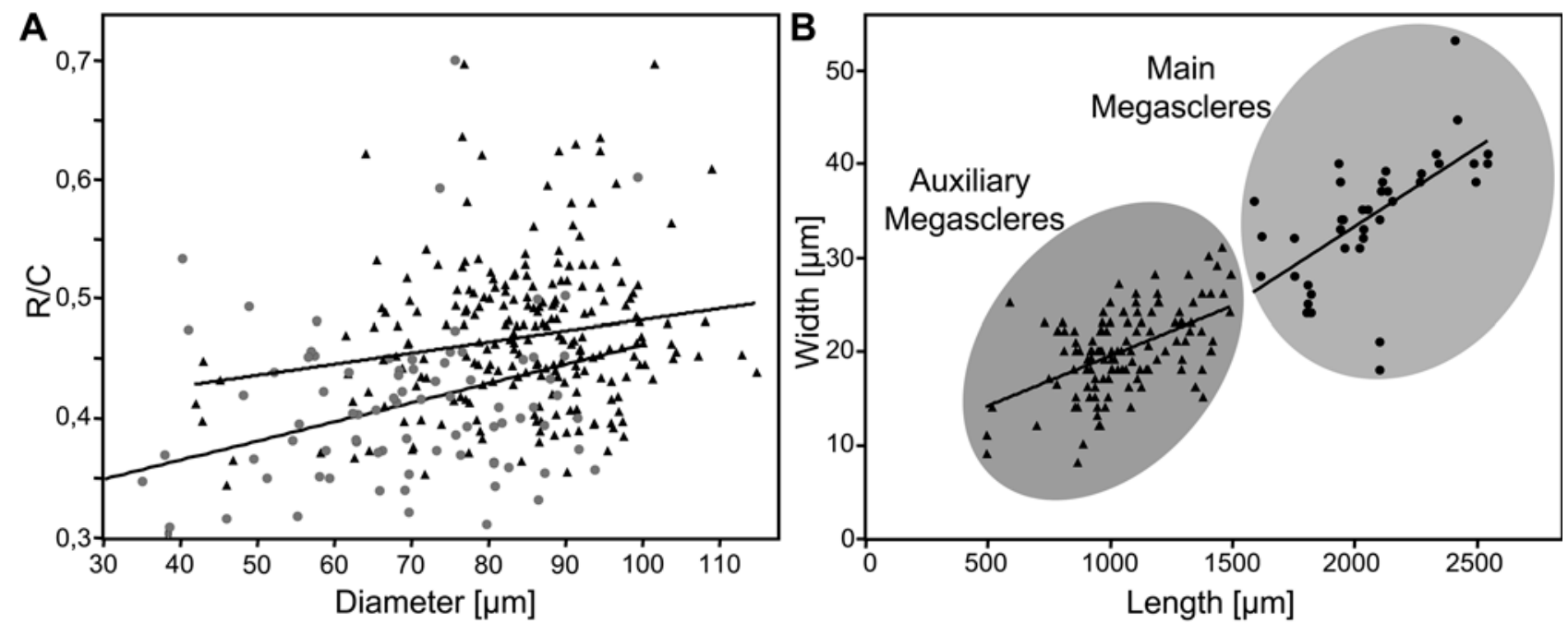

FIGURE 6. Morphometric correlations between megasters and megascleres in T. leysae sp. nov. A. Diameter of megasters vs. R/C ratio (ray length to radius of the massive spicule center), including linear fitted graphs. Choanosomal megasters (filled circles, $\mathrm{Ch}, \mathrm{n}=85$ ) are significantly smaller (independent $\mathrm{t}$-test; $\mathrm{p}<0.001$ ) than cortical megasters (filled triangles, $\mathrm{Co}, \mathrm{n}=227)$. The same applies to $\mathrm{R} / \mathrm{C}$ values, which are significantly lower for choanosomal megasters (independent t-test; $\mathrm{p}<0.001$ ), indicating more solid megasters with shorter rays and/or relatively more solid centers. Both differences are also represented by the linear fitted graphs. B. Length of megascleres plotted vs. width. Main and auxiliary megascleres represent two significantly different size classes, in terms of both length and width (independent $t-$ tests, $\mathrm{p}<0.001)$.

A Placospongia sp.

B

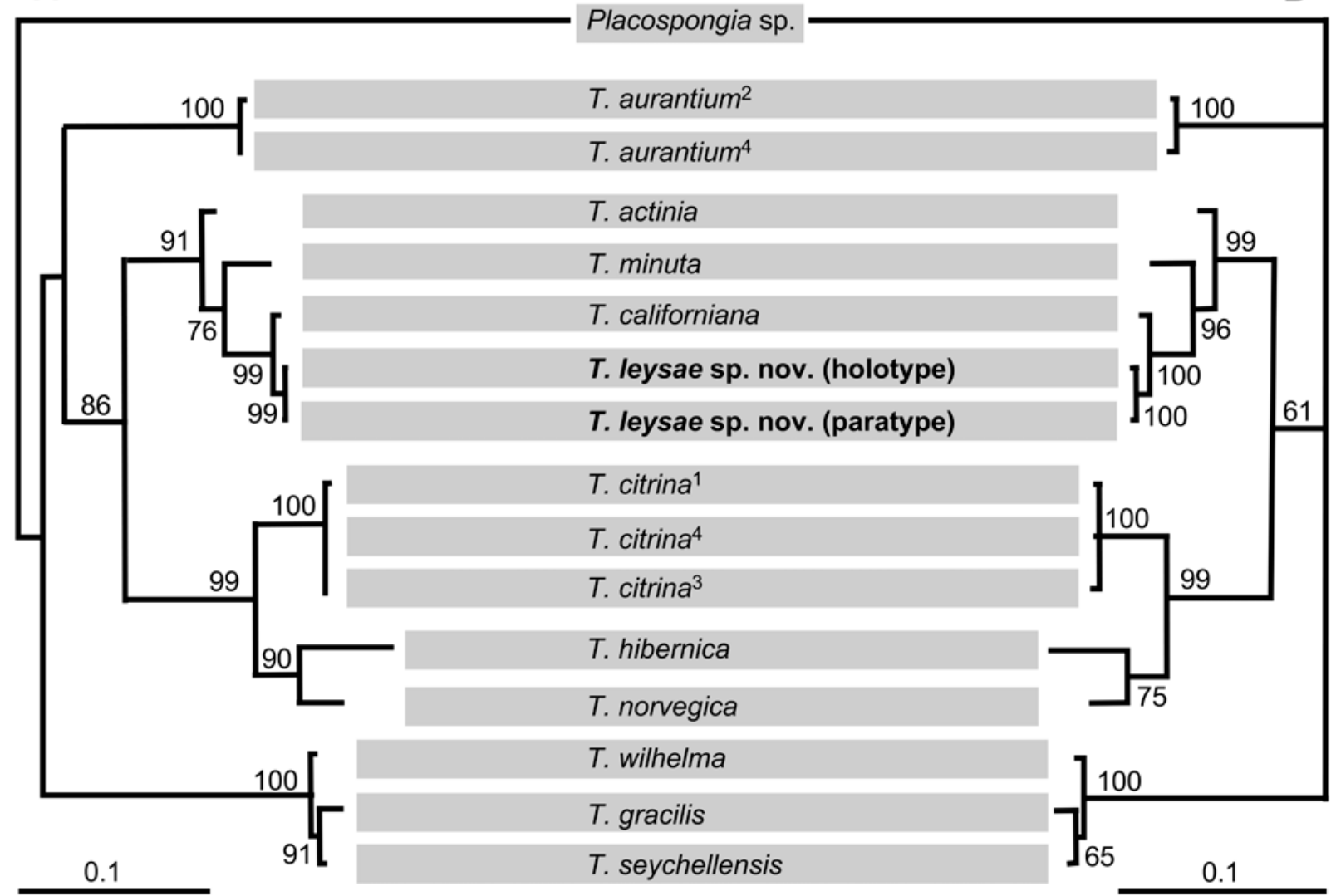

FIGURE 7. Phylogenetic consensus trees of COI sequences shown as a direct comparison between A. maximum likelihood (ML) and B. the 50\% majority rule consensus phylogram of the Bayesian approach. Numbers indicate bootstrap values (A) and posterior probabilities (B). Some species are represented by different sampling locations as indicated by indices: 1, Limski canal, Croatia; 2, Elba, Italy; 3, Rathlin Island, Northern Ireland; 4, Rovinj, Croatia. 

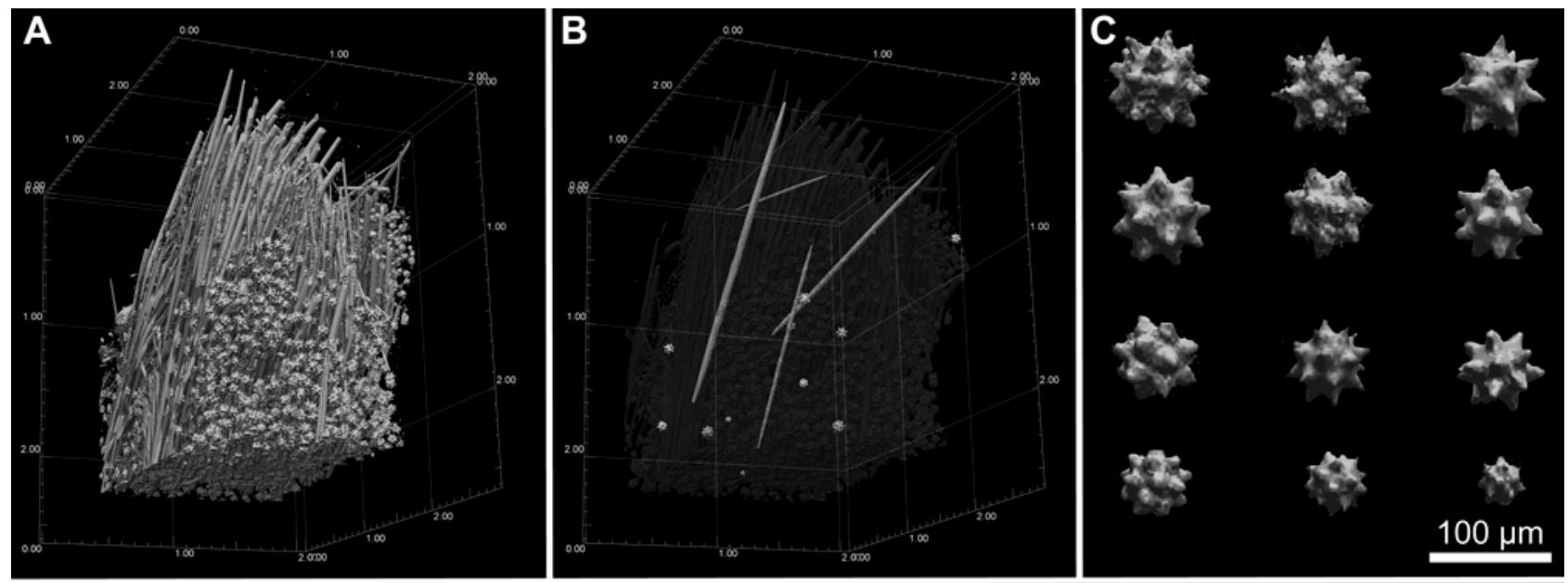

D

FIGURE 8. Virtual 3D isosurface rendering using VGStudio MAX of selected spicules within their skeletal context (A, B) and isolated from it (C, D), 3D-reconstructed from synchrotron radiation-based x-ray micro computed tomography images of the holotype. Virtual isolation (B) and comparative side-to side renderings of megasters $(\mathrm{C})$ and megascleres (D). Micrasters are visualized as small dots, e.g. in the peripheral region in A.

\section{Molecular genetic relationships of Tethya leysae sp. nov.}

A fragment of the cytochrome oxidase subunit I gene with $709 \mathrm{bp}$ was obtained for both specimens of $T$. leysae sp. nov. (NHM 2009.5.1.1 and PMJ Porif 287). Primer regions were excluded from the analysis, resulting in an effective length of $658 \mathrm{bp}$. The best matches of a BLAST search with T. leysae sp. nov. were T. californiana (AY561978), T. actinia (AY320033) and T. minuta (EF584567). The translation of the nucleotide sequences revealed amino acid sequences with a length of 216 amino acids.

Table 2 presents the pair-wise nucleotide and amino acid exchanges between various Tethya species. The highest rate of base pair exchanges occurred between T. norvegica, T. seychellensis and T. gracilis Sarà, Sarà, Nickel \& Brümmer, 2001 at 81 bp (2 aa), 80 bp (1 aa) and 80 bp (1 aa) respectively. For the transcribed amino acid sequences the highest substitution rate was found between T. leysae sp. nov. and T. seychellensis, at 6 aa (72 bp). The new species T. leysae sp. nov. differs from T. californiana in 4 bp and 2 aa.

The Bayesian analysis of the nucleotide sequence data resulted in a tree with three major branches which are basally not completely resolved (Figure 7B). The first branch (hereinafter the T. seychellensis complex) includes T. seychellensis (Vietnam) and the two species T. wilhelma and T. gracilis (biogeographic regions unknown). The second branch (hereinafter the actinia complex) is divided into two subgroups: one includes exclusively Mediterranean and North East Atlantic species (hereinafter the norvegica subgroup), and is made up of T. citrina (Limski canal \& Rovinj, Croatia; Rathlin Island, Northern Ireland), T. hibernica (Rathlin Island, Northern Ireland) and T. norvegica (Trondheimsfjord, Norway). The second subgroup (hereinafter the actinia subgroup) comprises $T$. actinia (Western Atlantic), T. minuta (biogeographic region unknown) $T$. californiana (Carmel-by-the-Sea, California, USA) and T. leysae sp. nov. (Barkley Sound, Canada). T. aurantium (Elba, Italy; Rovinj, Croatia) constitutes the third branch. 


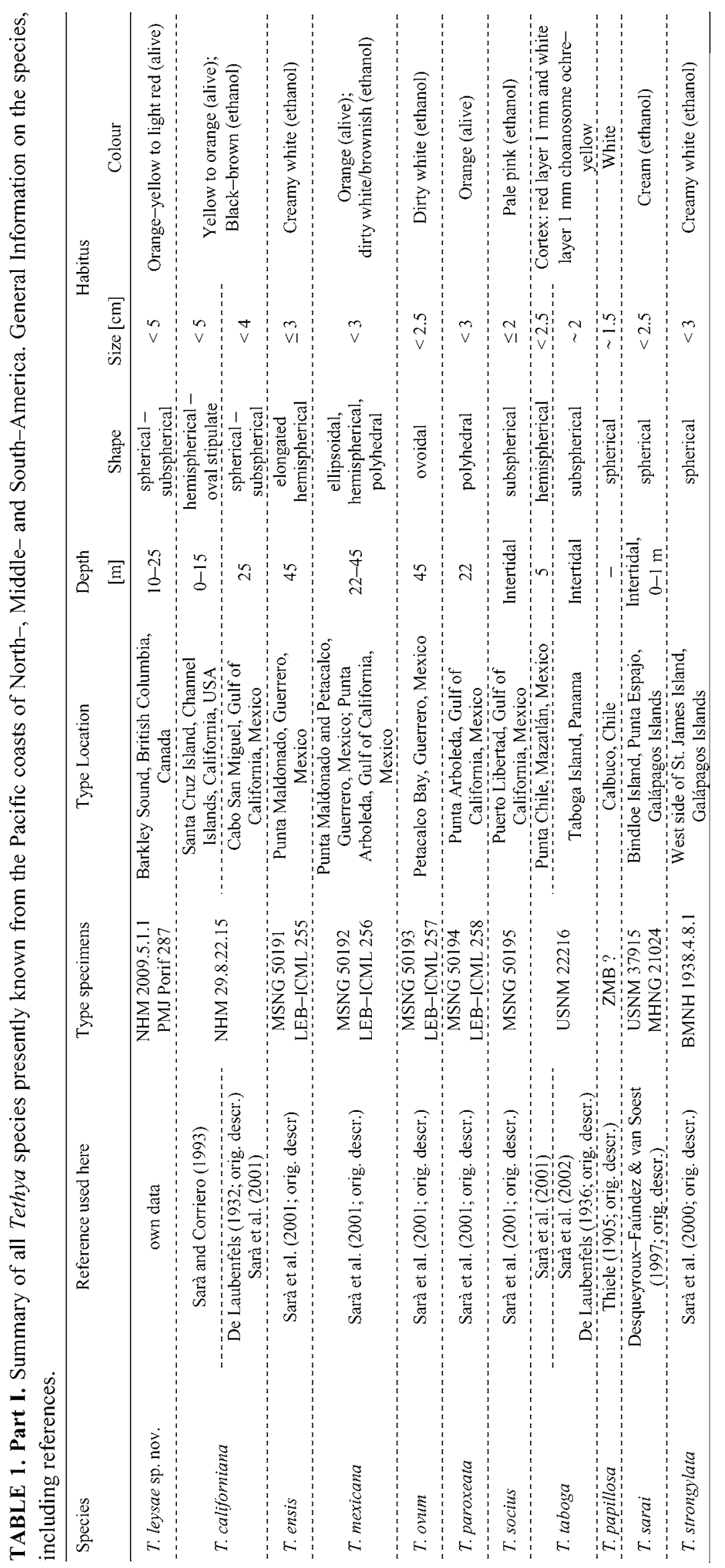




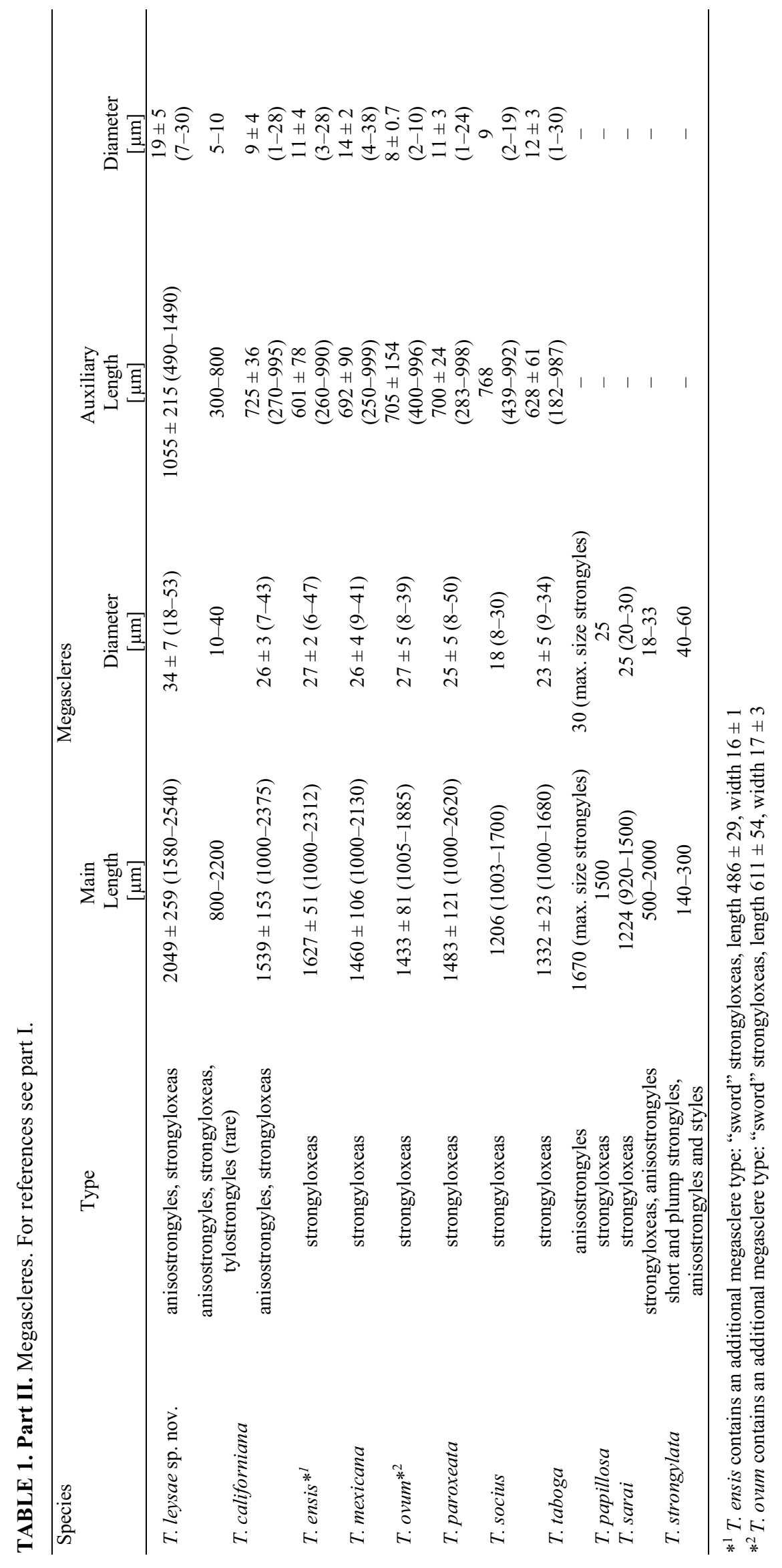




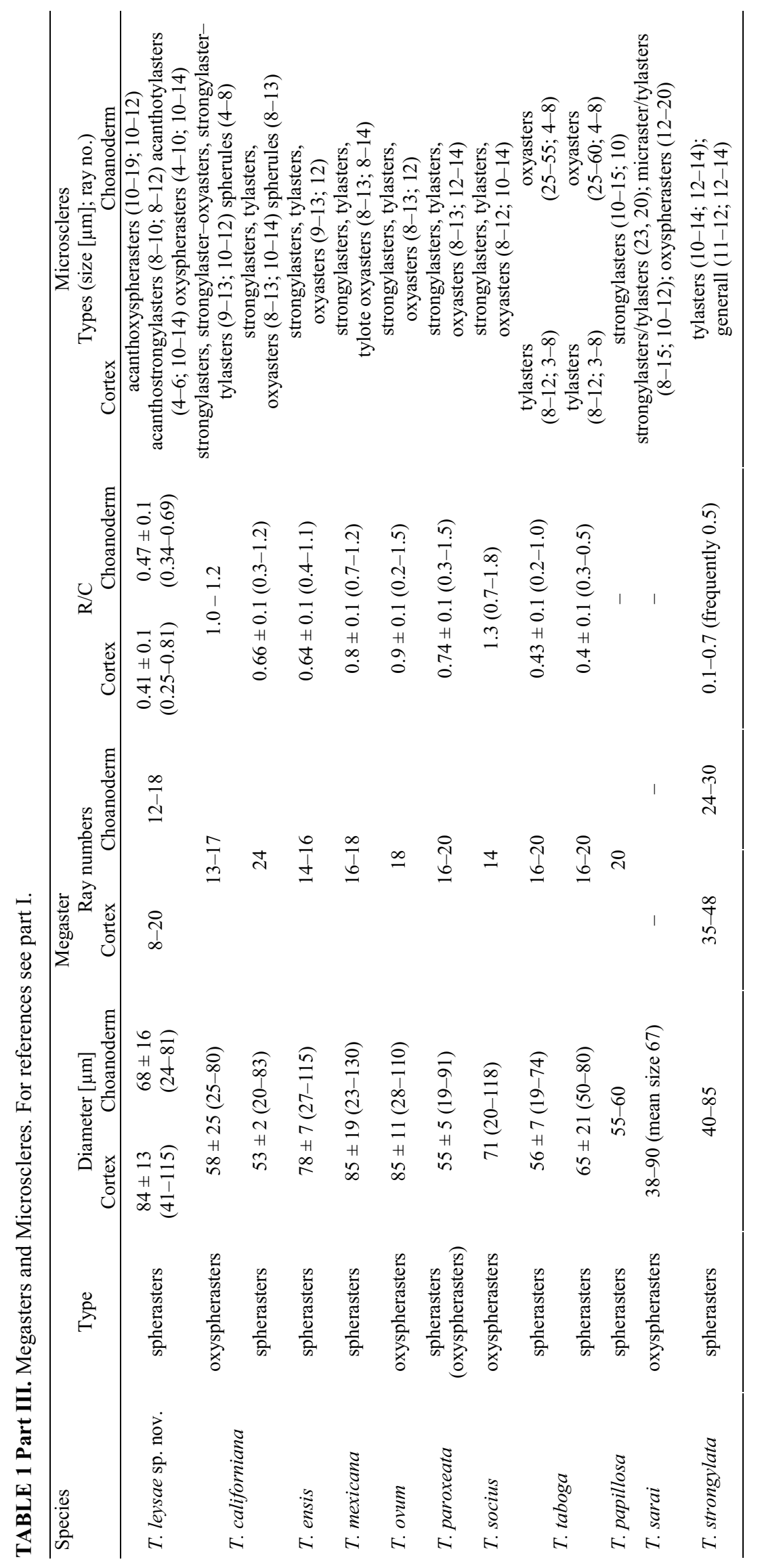


The result of our Maximum Likelihood analysis differs only slightly from that obtained using the Bayesian approach (Figure 7A). The same groups were recovered, with only one difference: T. aurantium appears to be the sister group of the citrina complex. Like in the Bayesian analysis, T. leysae sp. nov. appears to be closely related to $T$. californiana.

TABLE 2. Amino acid exchanges (upper section) and base pair exchanges (lower section) of the COI between different Tethya species. Indices refer to sampling locations in species for which more than one sample was included in the analysis: T. citrina $^{1}$ and T. aurantium $^{1}=$ Limski kanal, (Croatia), T. aurantium $^{2}=$ Elba (Italy), T. citrina $^{3}=$ Rathlin Island, Northern Ireland and T. citrina ${ }^{4}=$ Rovinj (Croatia); $\mathrm{BC} 1=$. leysae holotype; $\mathrm{BC} 2=T$. leysae paratype.

\begin{tabular}{|c|c|c|c|c|c|c|c|c|c|c|c|c|c|c|c|c|c|}
\hline & 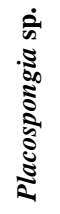 & 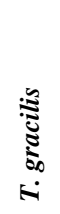 & 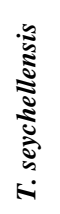 & 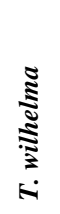 & - & 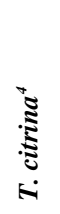 & 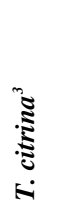 & 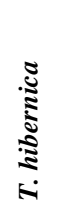 & 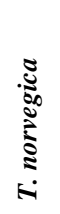 & ن & 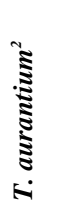 & 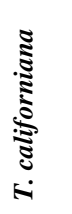 & 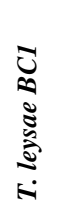 & 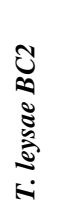 & 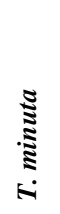 & ن & \\
\hline \multirow{3}{*}{$\begin{array}{c}\text { Placospongia sp. } \\
\text { T. gracilis } \\
\text { T. seychellensis }\end{array}$} & & 10 & 11 & 10 & 9 & 9 & 9 & 9 & 9 & 11 & 11 & 10 & 12 & 12 & 10 & 10 & \multirow{16}{*}{ 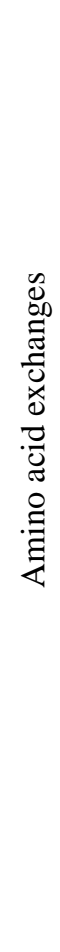 } \\
\hline & 96 & & 1 & 0 & 1 & 1 & 1 & 2 & 1 & 3 & 3 & 3 & 5 & 5 & 2 & 2 & \\
\hline & 93 & 7 & & 1 & 2 & 2 & 2 & 3 & 2 & 4 & 4 & 4 & 6 & 6 & 3 & 3 & \\
\hline T. wilhelma & 91 & 7 & 4 & & 1 & 1 & 1 & 2 & 1 & 3 & 3 & 3 & 5 & 5 & 2 & 2 & \\
\hline T. citrina ${ }^{l}$ & 92 & 76 & 73 & 70 & & 0 & 0 & 1 & 0 & 2 & 2 & 2 & 4 & 4 & 1 & 1 & \\
\hline T. citrina ${ }^{4}$ & 92 & 76 & 73 & 70 & 0 & & 0 & 1 & 0 & 2 & 2 & 2 & 4 & 4 & 1 & 1 & \\
\hline T. citrina $^{3}$ & 91 & 75 & 72 & 69 & 1 & 1 & & 1 & 0 & 2 & 2 & 2 & 4 & 4 & 1 & 1 & \\
\hline T. hibernica & 92 & 76 & 79 & 76 & 38 & 38 & 37 & & 1 & 3 & 3 & 3 & 5 & 5 & 2 & 2 & \\
\hline T. norvegica & 97 & 80 & 81 & 77 & 31 & 31 & 32 & 27 & & 2 & 2 & 2 & 3 & 3 & 1 & 1 & \\
\hline T. aurantium ${ }^{l}$ & 91 & 76 & 75 & 73 & 67 & 67 & 66 & 67 & 67 & & 0 & 4 & 4 & 4 & 1 & 1 & \\
\hline T. aurantium ${ }^{2}$ & 91 & 75 & 74 & 72 & 66 & 66 & 65 & 66 & 66 & 1 & & 4 & 4 & 4 & 1 & 1 & \\
\hline T. californiana & 92 & 72 & 69 & 67 & 54 & 54 & 55 & 60 & 52 & 54 & 54 & & 2 & 2 & 3 & 3 & \\
\hline T. leysae BCI & 95 & 77 & 72 & 71 & 56 & 56 & 57 & 60 & 54 & 52 & 52 & 4 & & 0 & 3 & 3 & \\
\hline T. leysae BC2 & 95 & 77 & 72 & 71 & 56 & 56 & 57 & 60 & 54 & 52 & 52 & 4 & 0 & & 3 & 3 & \\
\hline T. minuta & 85 & 68 & 65 & 63 & 55 & 55 & 56 & 64 & 56 & 53 & 53 & 20 & 22 & 22 & & 0 & \\
\hline T. actinia & 86 & 71 & 68 & 66 & 51 & 51 & 52 & 56 & 48 & 48 & 48 & 18 & 18 & 18 & 16 & & \\
\hline & \multicolumn{16}{|c|}{ Nucleotide base pair exchanges } & \\
\hline
\end{tabular}

\section{Microtomographic imaging, virtual reconstruction and in silico manipulations}

Using synchrotron radiation-based x-ray micro computed tomography, we imaged skeletal structures of $T$. leysae sp. nov. and used the information for our description of the species (Fig. 4). In addition, we used the dataset as a test case for the more general use of microtomography in sponge taxonomy. Figures $8 \mathrm{~A}-\mathrm{B}$ demonstrate the virtual in silico isolation of two main megascleres, two auxiliary megascleres and 12 megasters from the cortex of T. leysae. The same spicules are virtually isolated and arranged to scale for comparison in Figures $8 \mathrm{C}-\mathrm{D}$. Although the surface of the spicules appears rough as an effect of the resolution used, it is possible to measure them, count rays, and even calculate $\mathrm{R} / \mathrm{C}$ values for the megasters. Details of microscleres could not be reconstructed due to resolution limitations. However, their 3D distribution can be partly addressed, since they are visible as small dots in virtual 3D renderings (Fig 8A). 


\section{Discussion}

\section{Tethya leysae sp. nov. and T. californiana}

The new species Tethya leysae sp. nov. is an obvious member of the Hadromerida, characterized by the presence of asterose microscleres and of monaxonic megascleres which form a radiate skeleton (Hooper \& Van Soest 2002b, a). It is readily identified as a member of the Tethyidae by its globular growth form, the strongyloxeas which form radiate bundles and the presence of micrasters and megasters (Hooper \& Van Soest 2002b; Sarà 2002). Tethya leysae sp. nov. superficially resembles T. californiana in size, color and habitat preference. However, T. leysae sp. nov. lacks an alveolar cortex, and its cortex is densely packed with megasters. The massive cortex of T. leysae sp. nov. might be an adaptation to the prominent water current during tidal cycles. Additionally, megasters and micrasters differ between both species. They can be distinguished morphologically by careful analysis of the overall skeletal and spicule morphology as well as on the basis of $\mathrm{CO} 1$ "Folmer" fragment nucleotide sequences.

At present, T. leysae sp. nov. is only known from Barkley Sound (West coast of Vancouver Island, Canada). In contrast, four records are published for T. californiana (de Laubenfels 1932; Sarà \& Corriero 1993; Austin et al. 1999-2007; Nichols \& Barnes 2005). The holotype of T. californiana was found at Pescadero Point, near Carmel-by-the-Sea (California) (de Laubenfels 1932). Additional material for the redescription was collected near Santa Cruz, one of the Channel Islands near Santa Barbara (California) (Sarà \& Corriero 1993). The specimen used for COI sequencing (Genbank AY561978) was sampled close to the type location near Carmel-by-the-Sea (S. Nichols, personal communication). Apart from this, a species database record exists (GBIF 2009). It is possible that some Tethya records from the North American coast actually represent $T$. leysae which were misidentified as T. californiana. The question raises whether both species occur sympatrically or whether there is no geographical overlap between their populations.

The coastal province along the coast of California (where the syntypes of T. californiana were collected) is influenced by complex currents (McLain \& Thomas 1983; Kennett et al. 1997). The California Current transports cold arctic water from southern British Columbia into the California area. The inshore California Countercurrent drives warm waters from Baja California northwards. The resulting average annual water temperatures are $15.8^{\circ} \mathrm{C}$ for Santa Barbara near Santa Cruz Island and $12.1^{\circ} \mathrm{C}$ for Granit Canyon near Carmel (Scripps Institution of Oceanography 1981).

Vancouver Island (where T. leysae sp. nov. is found) is also influenced by the California Current flowing south and the Alaska Current flowing north (Francis et al. 1998; Kumar \& Patterson 2002). For Race Rocks in the South of Vancouver Island the annual average water temperature is $9.8^{\circ} \mathrm{C}$ (Fletcher 2009).

The hydrographic connection between the two areas with solid reports of T. leysae sp. nov. and T. californiana rather suggests that the sponge species are sympatric. The situation might actually resemble the partial overlap of habitat and of biogeographic areas as seen in some European species (Corriero et al. 1989; Heim et al. 2007b). However, we still lack significant biogeographical data for T. leysae sp. nov. and T. californiana.

\section{Remarks on the Eastern Pacific species of Tethya}

Apart from T. leysae sp. nov. and T. californiana, an additional nine species of Tethya are known from the Pan-American Eastern Pacific coasts (a comparative overview of morphological characters is presented in table 1). From the South American Pacific coasts (including the Galapagos Islands) three species are known: T. papillosa from Cabulco (Chile), and T. sarai and T. strongylata from the Galapagos Islands (Thiele 1905; Desqueyroux-Faúndez \& van Soest 1997; Sarà et al. 2001). Recently, five new species were described for the Pacific coast of Mexico and the Gulf of California. T. mexicana is distributed along the shore from Punta Libertad in the Gulf of California to Punta Maldonado at Guerrero in Southern Mexico. T. socius and T. paroxeata only occur in the Gulf of California and T. ovum and T. ensis in southern Mexico (Sarà et al. 2001). In the same study, T. taboga was found in Mexican waters for the first time. Including T. californiana (whose occurrence in the Gulf of California was also reported in the same study), the number of species found in the Mexican Pacific region adds up to seven (Sarà et al. 2001). 
Barcode sequencing these specimens (and the other Mexican species) would provide valuable insight into phylogenetic relationships. In our phylogenetic analyses (COI), T. leysae sp. nov. groups together with $T$. californiana as its closest relative, T. minuta and T. actinia (Fig.7). Unfortunately, the lack of molecular data on the Mexican species prevents us from confirming that these species also belong to the actinia species complex, as already suggested in the literature (Sarà et al. 2001). Future molecular studies on theses species as well as on all the Pacific species in general should resolve the phylogenetic context of the whole PanAmerican Tethya species cluster. The inclusion of more data from Atlantic species could shed light on the supposed close relationship between the majority of the Eastern Pacific species (such as T. leysae and T. californiana) and the Atlantic T. actinia.

Remarks on the use of microtomography in sponge taxonomy

Synchrotron radiation-based and conventional $\mathrm{x}$-ray micro computed tomography is typically within the methodological repertoire of the material sciences (Bonse \& Busch 1996; Beckmann 2008). In recent years, however, both applications have progressively found their way into the zoological sciences (Nickel et al. 2008). Microtomography combines the visual power of virtual 3D reconstruction (Zollikofer \& Ponce de León 2005) with the ability to resolve structures on the micrometer scale (Betz et al. 2007; Beckmann 2008; Nickel et al. 2008). As a result, it is generally used to address complicated morphological problems which are hard to understand via sections and other methods of preparation and imaging. Arthropods (i.e. members of Coleoptera and Arachnida) are among those which have been most extensively studied using microtomography (Beutel \& Haas 1998; Betz et al. 2007; Wirkner \& Prendini 2007; Beutel et al. 2008), but anatomic studies on small vertebrates such as amphibians (Kleinteich et al. 2008) have also benefited from the technique. Although microtomography has been used to analyze, qualitatively and quantitatively, the skeleton, tissue and canal system of the sponges T. minuta and T. wilhelma (Nickel et al. 2006a; Nickel et al. 2006b), it has never been used before for taxonomic purpose in sponge science. However, the value and power of microtomography for taxonomic purposes has been demonstrated on other animal groups, e.g. in recent studies on Siluriformes (Osteichthyes; Schaefer 2003) or Sooglossidae (Amphibia; Van Der Meijden et al. 2007), due to the possibility to precisely render any desired 3D-view of the complete specimens and parts of them, as well as virtually sectioned or isolated structures.

What are the advantages and limitations of microtomography in sponge taxonomy? The present example of T. leysae sp. nov. shows that the 3D structure of the silica skeleton can be visualized to some extent. However, in larger sponges - as in T. leysae sp. nov. - it is only possible to image parts of the skeleton, as the maximum resolution of microtomography is currently roughly $1 / 1000$ of the sample diameter. This is mainly dependent on the photographic chips used to record the absorption images needed for tomographic reconstruction via filtered back projection. Smaller sponge specimens can be imaged completely (Nickel et al. 2006a; Nickel et al. 2006b), or parts of a specimen can be used to reach resolutions of between 1 and $2 \mu \mathrm{m}$, which allows microscleres to be visualized (see figure 3C in Nickel et al. 2006a). Although this level of resolution is not likely to be high enough to analyze microsclere micromorphology in 3D, it does permit an analysis of megasters and megascleres such as styles (Fig. 8). Of course, SEM is superior in terms of resolution, but microtomography provides spatial information on the relationship between single selected spicules and the total skeleton. Microtomography is thus a useful addition to the toolbox of sponge taxonomy.

Nickel and co-workers have previously shown that it is possible to use 3D particle recognition algorithms to extract positional and size information for 16.000 megasters in the skeleton of a small specimen of $T$. minuta (Nickel et al. 2006a). At present, such algorithms need to be developed separately for each individual case with the help of mathematical software packages such as Matlab. This makes them unsuitable for wider taxonomic use. However, if a greater number of studies were to be performed, it would be worth developing more general particle recognition tools for in silico spicule analysis.

In addition to silica skeletons, calcareous spicules are also suitable for x-ray imaging as shown by a casestudy on Clathrina sp. (Nickel \& Beckmann, unpublished, images available upon request). Recently, we also successfully imaged the spongin skeleton of Collospongia auris Bergquist, Cambie \& Kernan, 1990 (Arnold $\&$ Nickel, unpublished, images available upon request), using osmium tetroxide contrasting to enhance the $\mathrm{x}$ - 
ray absorption of organic structures.

From the present study, we conclude that imaging isolated spicules embedded into a suitable matrix (paraffin, histological resins) would permit higher magnification/resolution and provide more detailed data on spicules. Restricted access to synchroton source beam lines makes it difficult to carry out new experiments in a timely manner following the evaluation of a study like the present one. However, modern desktop microtomographs provide an alternative. Even if they have not been tested on sponges yet, it can be concluded from other biological studies (Wirkner \& Prendini 2007) that they are suitable for imaging spicules and skeletons at adequate resolutions. Although synchrotron radiation-based microtomography results in more brilliant tomograms and thus allows higher x-ray density resolution, this is only relevant in the imaging of tissue rather than spicules. In contrast to synchrotron sources, which are not readily accessible and thus limit the number of possible measurements, desktop microtomographs would be affordable within a larger taxonomic project and thus provide high throughput in silico morphometry.

Conclusion and outlook

On the basis of examples from other biogeographic regions (Wörheide et al. 2000; Duran \& Rützler 2006; Blanquer \& Uriz 2007; Heim et al. 2007b), it seems likely that $T$. leysae sp. nov. might not be the only cryptic species along the Northeast Pacific coasts. In the case of T. leysae sp. nov., barcode sequencing of COI provided the hunch which was subsequently confirmed by morphological characters, mainly spicule morphology and morphometrics. However, more data is needed on the biogeography of T. leysae sp. nov. and T. californiana, and existing records should be carefully re-examined, in order to exclude or confirm sympatric occurrence and to sort out possible miss-identifications of already collected material.

We used x-ray microtomography for the first time to image and virtually reconstruct parts of the silica skeleton in 3D. The method allows spicule arrangements to be represented precisely, which in turn permits the comparative examination of thick sections or polished cuts under lower magnification using a compound microscope. Virtual reconstructions might even serve well for species determination purposes, then. The technique also reduces the need for the destructive sampling of valuable type specimens, since small specimens can be imaged completely and parts of larger specimens can be returned to the collection after scanning. X-ray microtomography, virtual reconstruction and in silico spicule/skeleton analysis will play an important role in sponge taxonomy once desktop microtomography scanners are more widely accessible within research institutes and museums.

\section{Acknowledgments}

We would like to thank Felix Beckmann and Julia Herzen (Hamburg) for SR- $\mu$ CT support and for performing filtered back projection of microtomographic image data; Jörg Hammel and Katja Felbel (Jena) for excellent assistance with sample preparations and at Hasylab beamline BW2 and SEM; Joana Xavier (Amsterdam) and Scott Nichols (Berkeley) for comments and discussion; Sally P. Leys (Edmonton) for providing sponge material, an in vivo photograph and habitat information. Two anonymous reviewers and the editor Eduardo Hajdu provided valuable comments which helped us to improve the manuscript. We thank Lucy Cathrow (Rostock) for improving the English. MN received microtomography beam time and financial support through DESY grant I-20060252. Financial support to IH and MN was provided by Friedrich-SchillerUniversity Jena through Martin S. Fischer.

\section{References}

Austin, B., Ott, B., McDaniel, N. \& Romagosa, P. (1999-2007) An annotated checklist of marine invertebrates in the cold temperate northeast Pacific, Khoyatan Marine Laboratory. Available from: http://www.mareco.org/KML/ Projects/NEsponges.asp (12.6.2009).

Beckmann, F. (2008) Neutron and Synchrotron-radiation based imaging for applications in materials science - from 
Macro- to Nanotomography. In: Reimers, W., Pyzalla, A.R., Schreyer, A. \& Clemens, H. (Eds.) Neutrons and synchrotron radiation in engineering materials science. Wiley-VCH, Weinheim, pp. 287-370.

Beckmann, F., Donath, T., Dose, T., Lippmann, T., Martins, R.V., Metge, J. \& Schreyer, A. (2004) Microtomography using synchrotron radiation at DESY: current status and future developments. Proceedings of SPIE, 5535, 1-10.

Bell, J.J. \& Barnes, D.K.A. (2001) Sponge morphological diversity: a qualitative preditor of species diversity? Aquatic Conservation: Marine And Freshwater Ecosystems, 11, 109-121.

Bergquist, P.R. \& Bedford, J.J. (1978) The incidence of antibacterial activity in marine Demospongiae; Systematic and geographic considerations. Marine Biology, 46, 215-221.

Bergquist, P.R., Sinclair, M.M. \& Hogg, J.J. (1970) Adaptation to intertidal existance, p. 247-271. In: Reproduction cycles and larval behaviour in Demospongia. Biology of Porifera. Fray, W.G. (ed.). Academic Press, London

Betz, O., Wegst, U., Weid, D., Heethoff, M., Helfen, L., Lee, W.-K. \& Cloethens, P. (2007) Imaging applications of synchrotron X-ray phase-contrast microtomography in biological morphology and biomaterials science. I. General aspects of the technique and its advantages in the analysis of millimetre-sized arthropod structure. Journal of Microscopy, 227, 51-71.

Beutel, R.G., Ge, S. \& Hörnschemeyer, T. (2008) On the head morphology of Tetraphalerus, the phylogeny of Archostemata and the basal branching events in Coleoptera. Cladistics, 24, 270-298.

Beutel, R.G. \& Haas, A. (1998) Larval head morphology of Hydroscapha natans (Coleoptera, Myxophaga) with reference to miniaturization and the systematic position of Hydroscaphidae. Zoomorphology, 118, 103-116.

Blanquer, A. \& Uriz, M.J. (2007) Cryptic speciation in marine sponges evidenced by mitochondrial and nuclear genes: A phylogenetic approach. Molecular Phylogenetics and Evolution, 45, 392-397.

Blanquer, A. \& Uriz, M.J. (2008) 'A posteriori' searching for phenotypic characters to describe new cryptic species of sponges revealed by molecular markers (Dictyonellidae: Scopalina). Invertebrate Systematics, 22, 489-502.

Blanquer, A., Uriz, M.J. \& Agell, G. (2008) Hidden diversity in sympatric sponges: adjusting life-history dynamics to share substrate. Marine Ecology Progress Series, 371, 109-115.

Bonse, U. \& Busch, F. (1996) X-Ray Computed Microtomography ( $\mu$ CT) using Synchrotron Radiation (SR). Progress in Biophysics and Molecular Biology, 65, 133-169.

Boury-Esnault, N., Klautau, M., Bézac, C., Wulff, J. \& Solé-Cava, A.M. (1999) Comparative study of putative conspecific sponge populations from both sides of the Isthmus of Panama. Journal of the Marine Biological Association of the United Kingdom, 79, 39-50.

Boury-Esnault, N., Marschal, C., Kornprobst, J.M. \& Barnathan, G. (2002) A new species of Axinyssa Lendenfeld, 1897 (Porifera, Demospongiae, Halichondrida) from the Senegalese coast. Zootaxa, 117, 1-8.

Boury-Esnault, N., Pansini, M. \& Uriz, M.J. (1993) Cosmopolitism in sponges: The "complex" Guitarra fimbriata with description of a new species of Guitarra from the northeast Atlantic. Scientia Marina, 57, 367-373.

Bowerbank, J.S. (1873) Contributions to a General History of the Spongiadae. Part IV. Proceedings of the Zoological Society of London, 1873, 3-25, pls. I-IV.

Burton, M. (1924) A revision of the sponge family Donatiidae. Proceeding of the zoological Society of London, 4, 10331046.

Corriero, G., Balduzzi, A. \& Sara, M. (1989) Ecological differences in the distribution of two Tethya (Porifera, Demospongiae) species coexisting in a Mediterranean coastal lagoon. Marine Ecology, 10, 303-315.

Costeloe, J., Keegan, B.F. \& Könnecker, G.F. (1986) Rocky subtidal assemblages on the west coast of Ireland. Hydrobiologia, 142, 97-111.

de Laubenfels, M.W. (1932) The marine and fresh-water sponges of California. Proceedings of the United States National Museum, 81, 1-140.

Desqueyroux-Faúndez, R. \& van Soest, R.W.M. (1997) Shallow water demosponges of the Galápagos Islands. Revue suisse de Zoologie, 104, 379-467.

Drummond, A., Ashton, B., Cheung, M., Heled, J., Kearse, M., Moir, R., Stones-Havas, S., Thierer, T. \& Wilson, A. (2009) Geneious 4.5 available from www.geneious.com

Duran, S. \& Rützler, K. (2006) Ecological speciation in a Caribbean marine sponge. Molecular Phylogenetics and Evolution, 40, 292-297.

Edgar, R.C. (2004) MUSCLE: multiple sequence alignment with high accuracy and high throughput. Nucl. Acids Res., 32, 1792-1797.

Erpenbeck, D., Voigt, O., Gültas, M. \& Wörheide, G. (2008) The Sponge Genetree Server - poviding a phylogenetic backbone for poriferan evolutionary studies. Zootaxa, 1939, 58-60.

Fletcher, G. (2009) Racerocks Ecological Reserve, Lester B. Pearson College of the Pacific. Available from: http:// www.racerocks.com (1.7.2009).

Folmer, O., Black, M., Hoch, W., Lutz, R. \& Vrijenhoek, R. (1994) DNA primers for amplification of mitochondrial cytochrome c oxidase subunit I from diverse metazoan invertebrates. Molecular Marine Biology and Biotechnology, 3, 294-299.

Forster, G.R. (1958) Underwater observations on the fauna of shallow rocky areas in the neighbourhood of Plymouth. 
Journal of the Marine Biological Association of the United Kingdom, 37, 473-482.

Francis, R.C., Hare, S.R., Hollowed, A.B. \& Wooster, W.S. (1998) Effects of interdecadal climate variability on the oceanic ecosystems of the NE Pacific. Fisheries Oceanography, 7, 1-21.

GBIF. (2009) Tethya californiana de Laubenfels, 1932; In database: Gwaii Haanas Invertebrates. Biodiversity occurrence data provided by: OBIS Canada (Accessed through GBIF Data Portal, www.gbif.net, 2009-06-16),

Heim, I., Nickel, M. \& Brümmer, F. (2007a) Phylogeny of the genus Tethya (Tethyidae: Hadromerida: Porifera): molecular and morphological aspects. Journal of the Marine Biological Association of the UK, 87, 1615-1627.

Heim, I., Nickel, M., Picton, B. \& Brümmer, F. (2007b) Description and molecular phylogeny of Tethya hibernica sp. nov. (Porifera, Demospongiae) from Northern Ireland with remarks on the European species of the genus Tethya. Zootaxa, 1595, 1-15.

Hooper, J.N.A. \& Van Soest, R.W.M. (2002a) Class Demospongiae Sollas,1885. In: Hooper, J.N.A. \& van Soest, R.M.W. (Eds.) Systema Porifera: A Guide to the Classification of Sponges. Kluwer Academic/Plenum Publishers, New York, pp. 15-18.

Hooper, J.N.A. \& Van Soest, R.W.M. (2002b) Order Hadromerida Topsent, 1894. In: Hooper, J.N.A. \& van Soest, R.M.W. (Eds.) Systema Porifera: A Guide to the Classification of Sponges. Kluwer Academic/Plenum Publishers, New York, pp. 169-172.

Huesman, R., Gullberg, G., Greenberg, W. \& TF, B. (1977) RECLBL Library users manual: Donner algorithms for reconstruction tomography. Lawrence Berkeley Laboratory, University of California, Livermore, pp.

Kelly-Borges, M. \& Pomponi, S. (1992) The simple fool's guide to sponge taxonomy. Harbor Branch Oceanographic Institution, Fort Pierce, Florida

Kennett, D.J., Ingram, B.L., Erlandson, J.M. \& Walker, P. (1997) Evidence for temporal fluctuations in marine radiocarbon reservoir ages in the Santa Barbara Channel, Southern California. Journal of Archaeological Science, 24, 1051-1059.

Klautau, M., Solé-Cava, A.M. \& Borojecic, R. (1994) Biochemical systematics of sibling sympatric species of Clathrina (Porifera: Calcarea). Biochemical Systematics And Ecology, 22, 367-375.

Kleinteich, T., Beckmann, F., Herzen, J., Summers, A.P. \& Haas, A. (2008) Applying X-ray tomography in the field of vertebrate biology: form, function, and evolution of the skull of caecilians (Lissamphibia: Gymnophiona), p. 70780D-10. In: Developments in X-Ray Tomography VI. Vol. 7078. SPIE, San Diego, CA, USA

Kumar, A. \& Patterson, R.T. (2002) Dinoflagellate cyst assemblages from Effingham Inlet, Vancouver Island, British Columbia, Canada. Palaeogeography, Palaeoclimatology, Palaeecology, 180, 187-206.

McLain, D.R. \& Thomas, D.H. (1983) Year-to-year fluctuations of the California Countercurrent and effects on marine organisms. California Cooperative Oceanic Fischeries Investigations, 24, 165-181.

Miller, K., Alvarez, B., Battershill, C., Northcote, P. \& Parthasarathy, H. (2001) Genetic, morphological, and chemical divergence in the sponge genus Latrunculia (Porifera: Demospongiae) from New Zealand. Marine Biology, 139, 235-250.

Murch, A. (2009) The BC Marinelife Index, Available at http://elasmodiver.com/BCMarinelife/bc_marinelife_index.htm (accessed 2009-06-16).

Nichols, S.A. \& Barnes, P.A.G. (2005) A molecular phylogeny and historical biogeography of the marine sponge genus Placospongia (Phylum Porifera) indicate low dispersal capabilities and widespread crypsis. Journal of Experimental Marine Biology and Ecology, 323, 1-15.

Nickel, M., Bullinger, E. \& Beckmann, F. (2006a) Functional morphology of Tethya species (Porifera): 2. Threedimensional morphometrics on spicules and skeleton superstructures of T. minuta. Zoomorphology, 125, $225-239$.

Nickel, M., Donath, T., Schweikert, M. \& Beckmann, F. (2006b) Functional morphology of Tethya species (Porifera): 1. Quantitative 3D-analysis of Tethya wilhelma by synchrotron radiation based X-ray microtomography. Zoomorphology, 125, 209-223.

Nickel, M., Hammel, J., Herzen, J., Bullinger, E. \& Beckmann, F. (2008) High density resolution synchrotron radiation based x-ray microtomography (SR $\mu \mathrm{CT}$ ) for quantitative 3D-morphometrics in zoological sciences. Proceedings of SPIE, 7078, 7078W.

Nylander, J.A.A., Ronquist, F., Huelsenbeck, J.P. \& Aldrey, J.L.N. (2004) Bayesian phylogenetic analysis of combined data. Systematic Biology, 53, 47-67.

Page, R.D.M. (1996) TreeView: An application to display phylogenetic trees on personal computers. Computer Applications in the Biosciences, 12, 357-358.

Rasband, W.S. (1997-2009) ImageJ. National Institutes of Health, Bethesda, Maryland, USA; http://rsb.info.nih.gov/ij/

Ronquist, F. \& Huelsenbeck, J.P. (2003) MRBAYES 3: Bayesian phylogenetic inference under mixed models. Bioinformatics, 19, 1572-1574.

Sarà, M. (1998) A Biogeographic and Evolutionary Survey of the Genus Tethya (Porifera, Demospongiae). In: Watanabe, Y. \& Fusetani, N. (Eds.) Sponge Sciences. Multidisciplinary Perspectives. Springer, Tokyo, pp. 83-94.

Sarà, M. (2002) Family Tethyidae Gray 1848. In: Hooper, J.N.A. \& van Soest, R.M.W. (Eds.) Systema Porifera: A Guide to the Classification of Sponges. Kluwer Academic/Plenum Publishers, New York, pp. 245-265. 
Sarà, M., Bavestrello, G. \& Mensi, P. (1992) Redescription of Tethya norvegica Bowerbank (Porifera, Demospongiae), with remarks on the genus Tethya in the North East Atlantic. Zoologica Scripta, 21, 211-216.

Sarà, M. \& Corriero, G. (1993) Redescription of Tethya californiana De Laubenfels as a valid species for Tethya aurantia var. californiana (Porifera, Demospongiae). Ophelia, 37, 203-211.

Sara, M. \& Gaino, E. (1987) Interspecific variation in arrangement and morphology of micrasters of Tethya species (Porifera, Demospongiae). Zoomorphology, 107, 313-317.

Sarà, M., Gómez, P. \& Sarà, A. (2001) East Pacific Mexican Tethya (Porifera: Demospongiae) with descriptions of five new species. Proceedings of the Biological Society of Washington, 114, 794-821.

Sarà, M. \& Melone, N. (1965) Una nuova specie del genere Tethya, T. citrina sp. n. dal Mediterraneo (Porifera, Demospongiae). Atti della Società Peloritana di Scienze fisiche matematiche e naturali, 11, 123-138.

Sarà, M., Mensi, P., Manconi, R., Bavestrello, G. \& Balletto, E. (1989) Genetic variability in Mediterranean Sea populations of Tethya (Porifera: Demospongiae). In: Ryland, J.S. \& Tyler, P.A. (Eds.) Reproduction, genetics and distributions of marine organisms 293-298. Olsen \& Olsen, Fredensborg, pp. 293-298.

Sarà, M. \& Sarà, A. (2004) A revision of Australian and New Zealand Tethya (Porifera:Demospongiae) with a preliminary analysis of species grouping. Invertebrate Systematics, 18, 117-156.

Schaefer, S.A. (2003) Relationships of Lithogenes villosus Eigenmann, 1909 (Siluriformes, Loricariidae): Evidence from High-Resolution Computed Microtomography. American Museum Novitates, 1-55.

Scripps Institution of Oceanography. (1981) Surface water temperatures at shore stations. United States West Coast 1980, p. 45. Marine Life Research Committee and Marine Life Research Group, University of California, Scripps Institution of Oceanography, La Jolla, California

Sim, C.J. (1981) A taxonomic study on the marine sponges in Korea [R.], 2: Hadromerida. Korean Journal of Zoology, 24, 9-17.

Solé-Cava, A.M., Klautau, M., Boury-Esnault, N., Borojecic, R. \& Thorpe, J.P. (1991) Genetic evidence for cryptic speciation in allopatric populations of two cosmopolitan species of the calcareous sponge genus Clathrina. Marine Biology, 111, 381-386.

Solé-Cava, A.M. \& Thorpe, J.P. (1986) Genetic differentiation between morphotypes of the marine sponges Suberites ficus (Demospongiae: Hadromerida). Marine Biology, 93, 247-253.

Solé-Cava, A.M. \& Thorpe, J.P. (1987) The use of electrophoresis in sponge taxonomy. NATO ASI Series - Taxonomy of Porifera, G 13, 243-258.

Stamatakis, A., Hoover, P. \& Rougemont, J. (2008) A Rapid Bootstrap Algorithm for the RAxML Web Servers. Systematic Biology, 57, $758-771$.

Tatusov, T. \& Tatusov, R. (1988-2009) ORF Finder (Open Reading Frame Finder), National Center for Biotechnology Information (NCBI) Available from: http://www.ncbi.nlm.nih.gov/gorf/gorf.html

Thiele, J. (1905) Die Kiesel- und Hornschwämme der Sammlung Plate. Zoologische Jahrbücher, Supplement 6, 107496.

Topsent, E. (1918) Eponges de San Thome. Essai sul les genres Spirastrella, Donatia et Chondrilla. Archives de zoologie experimentale et generale, 57, 535-618.

Van Der Meijden, A., Boistel, R., Gerlach, J., Ohler, A., Vences, M. \& Meyer, A. (2007) Molecular phylogenetic evidence for paraphyly of the genus Sooglossus, with the description of a new genus of Seychellean frogs. Biological Journal of the Linnean Society, 91, 347-359.

Van Soest, R.W.M., Boury-Esnault, N., Hooper, J.N.A., Rützler, K., de Voogd, N.J., Alvarez, B., Hajdu, E., Pisera, A.B., Vacelet, J., Manconi, R., Schoenberg, C., Janussen, D., Tabachnick, K.R. \& Klautau, M. (2009) World Porifera database. Available online at http://www.marinespecies.org/porifera. Consulted on 2009-06-19. Available from:

Wirkner, C.S. \& Prendini, L. (2007) Comparative morphology of the hemolymph vascular system in scorpions-A survey using corrosion casting, MicroCT, and 3D-reconstruction. Journal of Morphology, 268, 401-413.

Wörheide, G., Degnan, B.M., Hooper, J.N.A. \& Reitner, J. (2000) Phylogeography and taxonomy of the Indo-Pacific reef cave dwelling coralline demosponge Astrosclera 'willeyana': new data from nuclear internal transcribed spacer sequences, p. 339-346. In: 9th International Coral Reef Symposium. Vol. 1. Moosa, K. (ed.), Bali

Wulff, J.L. (2006) Sponge systematics by starfish: predators distinguish cryptic sympatric species of Caribbean fire sponges, Tedania ignis and Tedania klausi n. sp. (Demospongiae, Poecilosclerida). Biological Bulletin, 211, 83-94.

Xavier, J.R., Rachello-Dolmen, P.G., Parra-Velandia, F., Schöneberge, C.H.L., Breeuwer, J.A.J. \& Van Soest, R.W.M. (2009) Molecular evidence of cryptic speciation in the "cosmopolitan"excavating sponge Cliona celata (Porifera, Clionaidae). under review.

Zollikofer, C. \& Ponce de León, M. (2005) Virtual Reconstruction. A Primer in Computer-Assisted Paleontology and Biomedicine. Wiley \& Sons, New York, pp. 